\title{
2018 International Olympic Committee consensus statement on prevention, diagnosis and management of paediatric anterior cruciate ligament (ACL) injuries
}

\section{Citation}

Ardern, C. L., G. R. Ekås, H. Grindem, H. Moksnes, A. F. Anderson, F. Chotel, M. Cohen, et al. 2018. "2018 International Olympic Committee consensus statement on prevention, diagnosis and management of paediatric anterior cruciate ligament (ACL) injuries." British Journal of Sports Medicine 52 (7): 422-438. doi:10.1136/bjsports-2018-099060. http://dx.doi.org/10.1136/ bjsports-2018-099060.

\section{Published Version}

doi:10.1136/bjsports-2018-099060

\section{Permanent link}

http://nrs.harvard.edu/urn-3:HUL.InstRepos:35981881

\section{Terms of Use}

This article was downloaded from Harvard University's DASH repository, and is made available under the terms and conditions applicable to Other Posted Material, as set forth at http:// nrs.harvard.edu/urn-3:HUL.InstRepos:dash.current.terms-of-use\#LAA

\section{Share Your Story}

The Harvard community has made this article openly available.

Please share how this access benefits you. Submit a story.

\section{Accessibility}




\section{(2) OPEN ACCESS}

- Additional material is published online only. To view, please visit the journal online (http://dx.doi.org/10.1136/ bjsports-2018-099060).

For numbered affiliations see end of article.

Correspondence to Dr Clare L Ardern, School of Allied Health, La Trobe University, Melbourne, VIC 3086, Australia; c.ardern@latrobe.edu.au

This article has been copublished in the Journal of ISAKOS, Orthopaedic Journal of Sports Medicine and Knee Surgery Sports Traumatology Arthroscopy.

Accepted 23 January 2018 Published Online First 24 February 2018

\section{Linked}

- http://dx.doi.org/10.1136/ bjsports-2018-099169

Check for updates

To cite: Ardern $\mathrm{CL}$, Ekås $\mathrm{GR}$, Grindem $\mathrm{H}$, et al. Br J Sports Med 2018;52:422-438

\title{
2018 International Olympic Committee consensus statement on prevention, diagnosis and management of paediatric anterior cruciate ligament $(\mathrm{ACL})$ injuries
}

\author{
Clare L Ardern, ${ }^{1,2}$ Guri Ranum Ekås, ${ }_{1}^{3,4,5}$ Hege Grindem ${ }^{6}$ Håvard Moksnes, ${ }^{4}$ \\ Allen F Anderson, ${ }^{7}$ Franck Chotel, ${ }^{8}$ Moises Cohen, ${ }^{9}$ Magnus Forssblad, ${ }^{10}$ \\ Theodore J Ganley, ${ }_{11}^{11}$ Julian A Feller, ${ }^{12,13}$ Jón Karlsson, ${ }^{14}$ Minider S Kocher, ${ }^{15,16}$ \\ Robert F LaPrade, ${ }^{17,18}$ Michael McNamee, ${ }^{19}$ Bert Mandelbaum ${ }^{20}{ }^{20}$ Lyle Micheli, ${ }^{15,16,21}$ \\ Nicholas Mohtadi, ${ }^{22}$ Bruce Reider, ${ }^{23}$ Justin Roe ${ }_{1}{ }^{24}$ Romain Seil, ${ }^{25,26}$ Rainer Siebold, ${ }^{27,28}$ \\ Holly J Silvers-Granelli, ${ }^{29}$ Torbjørn Soligard, ${ }^{30,31}$ Erik Witvrouw, $^{32}$ \\ Lars Engebretsen $3,4,5,30$
}

\section{ABSTRACT}

In October 2017, the International Olympic Committee hosted an international expert group of physiotherapists and orthopaedic surgeons who specialise in treating and researching paediatric $A C L$ injuries. Representatives from the American Orthopaedic Society for Sports Medicine, European Paediatric Orthopaedic Society, European Society for Sports Traumatology, Knee Surgery \& Arthroscopy, International Society of Arthroscopy Knee Surgery and Orthopaedic Sports Medicine, Pediatric Orthopaedic Society of North America and Sociedad Latinoamericana de Artroscopia, Rodilla y Deporte attended. Physiotherapists and orthopaedic surgeons with clinical and research experience in the field, and an ethics expert with substantial experience in the area of sports injuries also participated. Injury management is challenging in the current landscape of clinical uncertainty and limited scientific knowledge. Injury management decisions also occur against the backdrop of the complexity of shared decision-making with children and the potential long-term ramifications of the injury. This consensus statement addresses six fundamental clinical questions regarding the prevention, diagnosis and management of paediatric $A C L$ injuries. The aim of this consensus statement is to provide a comprehensive, evidence-informed summary to support the clinician, and help children with ACL injury and their parents/guardians make the best possible decisions.

\section{INTRODUCTION}

The number of ACL injuries in children is rising. ${ }^{12}$ ACL injuries in children create a level of concern that is more significant than in any other population with ACL injury. Do children who rupture their ACL mature similarly to their uninjured peers? Do they continue with sport? Do they prioritise their education and other interests over sport? Does an ACL injury and treatment change their lives? These young individuals have to live with their knee problem for the rest of their life, which may compromise their quality of life and increase the risk for further injury, meniscal tears and early onset osteoarthritis. ${ }^{3}$ Compounding the problem is that there is very little high-quality evidence to guide decision-making in management of paediatric ACL injuries. ${ }^{4}$

Progress on these issues can only be made based on long-term follow-up in multicentre collaborations. Achieving progress requires a long-term commitment from those who have children's interests close at heart. Therefore, in October 2017, the IOC hosted an international expert group of physiotherapists and orthopaedic surgeons who specialise in treating and researching paediatric ACL injuries. Representatives from the following societies attended: American Orthopaedic Society for Sports Medicine (AOSSM), European Paediatric Orthopaedic Society, European Society for Sports Traumatology, Knee Surgery \& Arthroscopy (ESSKA), International Society of Arthroscopy Knee Surgery and Orthopaedic Sports Medicine (ISAKOS), Pediatric Orthopaedic Society of North America and Sociedad Latinoamericana de Artroscopia, Rodilla y Deporte (SLARD).

Clinicians are charged with the responsibility of providing accurate information and effective treatment to this vulnerable population. Sharing information about the potential consequences of ACL injury and treatment in childhood to longterm knee health should be a central part of the shared decision-making process. Adult patients with ACL injury may develop symptoms and signs of osteoarthritis within 10 years of the index injury. ${ }^{5}$ Therefore, the clinical concern is that a child who is injured at the age of 10 years could have symptomatic osteoarthritis by the age of 20. A quintessential question is what is the long-term prognosis after ACL injury in childhood? Having a definitive, evidence-based answer to this question would strengthen our confidence in clinical decision-making. Clearly, the answer to this question is not straightforward and depends on many factors, but one important point is that long-term outcomes 
Box 1 Six fundamental clinical questions and relevant consensus statement topic(s)

Section 1: How can the clinician prevent $\mathrm{ACL}$ injuries in children?

Relevant consensus statement topic:

- Injury prevention

Section 2: How does the clinician diagnose ACL injuries in children?

Relevant consensus statement topic:

- Diagnostic tests and imaging

Section 3: What are the treatment options for the child with an ACL injury?

Relevant consensus statement topics:

- High-quality rehabilitation

- Surgical techniques

- The paediatric $A C L$ graft

Section 4: What are the most important considerations when making treatment decisions?

Relevant consensus statement topics:

- Skeletal age assessment

- The decision for $\mathrm{ACL}$ reconstruction

- Risks associated with $\mathrm{ACL}$ reconstruction

- Management of associated injuries

Section 5: How does the clinician measure outcomes that are relevant to the child with an ACL injury?

Relevant consensus statement topic:

- Paediatric patient-reported outcome measures

Section 6: What are the clinician's role and responsibilities?

Relevant consensus statement topic:

- Ethical considerations

after ACL injury in childhood, including the development of osteoarthritis, have not been studied.

\section{'Long-term outcomes after ACL injury in childhood, including the development of osteoarthritis, have not been studied.'}

Injury management is challenging in the current landscape of clinical uncertainty and limited scientific knowledge. Injury management decisions also occur against the backdrop of the complexity of shared decision-making with children and the potential long-term ramifications of the injury. This consensus statement addresses six fundamental clinical questions regarding the prevention, diagnosis and management of paediatric ACL injuries (box 1). By framing each topic around clinical questions, the aim of this consensus statement is to provide a comprehensive, evidence-informed summary to support the clinician, and help children with ACL injury and their parents/guardians make the best possible decisions.

\section{CONSENSUS METHODS}

A modified Delphi consensus process ${ }^{6-8}$ was used to identify the topics to be addressed in this consensus statement. Experts were contacted by email in June 2016, and invited to respond to an electronic survey. A mix of open and closed questions were used to gather expert opinion regarding the key issues in the field. These responses were summarised and formed the basis of 18 statements regarding injury prevention, diagnosis, prognosis, surgical techniques, treatment decision-making, management and outcome measurement (see online supplementary file 1) .

A two-round consensus process was conducted, involving 19 content experts. Respondents rated the importance of the 18 predefined statements on an 11-point scale ranging from not important at all to of utmost importance. Consensus was defined as a mean ranking of at least eight points for each statement. After the first voting round, statements reaching consensus were removed, so that only statements that failed to reach consensus in the first voting round went through to the second voting round. The statements that finally reached consensus formed the topics that were discussed at the consensus meeting.

The IOC convened a consensus meeting of 21 experts in Lausanne, Switzerland in October 2017. The experts were identified by the IOC through the AOSSM, ESSKA, ISAKOS and SLARD member societies, and from physiotherapists and orthopaedic surgeons with clinical and research experience in the field. An ethics expert with substantial experience in the area of sports injuries also participated.

\section{Section 1: injury prevention}

This section addresses the fundamental clinical question: how can the clinician prevent ACL injuries in children? Prevention of ACL injury is important because of the potential for serious long-term consequences in those who sustain the injury, and because of the increased risk of reinjury to either knee. ${ }^{9}$ Therefore, it is paramount that the principles of injury prevention are incorporated in the treatment of the child with ACL injury.

Substantial advances have been made in the development and application of ACL injury prevention programs across numerous pivoting sports. There is compelling evidence that ACL injury prevention programs work in skeletally mature patients-they reduce the number of athletes who sustain a primary ACL injury, and reduce the number of new ACL injuries among athletes who return to sport after primary ACL injury. ${ }^{10-15}$

The athlete's biomechanical movement patterns are a key modifiable risk factor for injury. Injury prevention programs target movement patterns by incorporating strength, plyometrics and sports-specific agility training. ${ }^{16}{ }^{17}$ Coach and athlete education on cutting/landing techniques (eg, wide foot position when cutting, flexed knee when landing) that avoid high-risk knee positions are also fundamental. Injury prevention programs are straightforward to implement because they require little to no equipment, and are performed as part of regular team training or physical education 2-3 times per week (figure 1).

\section{'11+ For Kids' program}

\section{'Injury prevention programs should also be implemented early in the athlete's developmental process.'}

Injury prevention programs should also be implemented early in the athlete's developmental process. This will give the athlete the best opportunity to develop strong and favourable movement strategies. One well-established injury prevention program, ${ }^{18}$ the $11+$, has recently been modified (eg, adding falling techniques, making partner-based exercises more play-oriented) to suit the paediatric population (FIFA '11 + For Kids'). Completing 


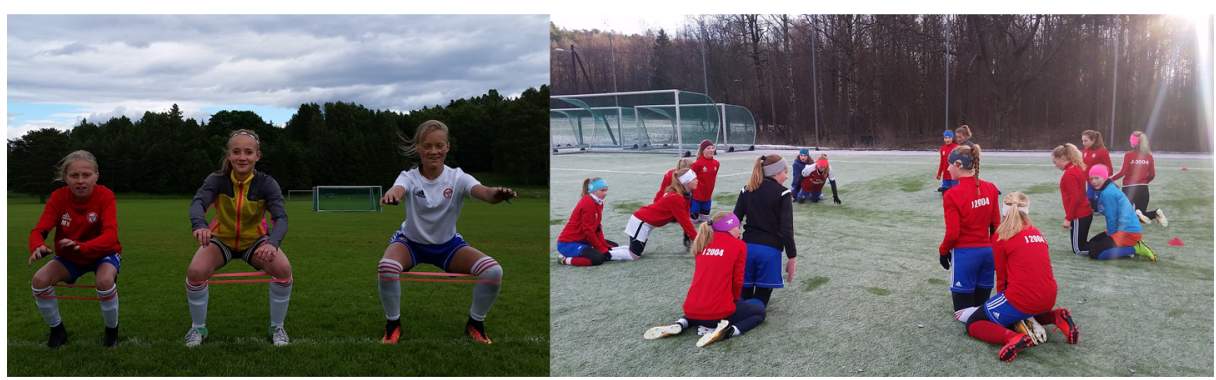

Figure 1 Injury prevention exercises incorporated into team training.

the program can reduce football-related lower extremity injuries by over half. ${ }^{19}$ Children who complete the program also have improved motor control, balance tests and agility, compared with those who do not complete the program. ${ }^{20}$

Factors that might impact on injury prevention effectiveness Well-designed injury prevention programs have the lowest injury rates and injury time loss. ${ }^{18} 21$ But the effect of a well-designed injury prevention program is strongly influenced by how frequently athletes perform the training. ${ }^{22-24}$ Therefore, consistent implementation and utilisation, and adherence across all levels of competitive play, is one of the biggest challenges facing the clinician. Those involved in youth sports, and clinicians who treat paediatric athletes with ACL injury have a responsibility to actively advocate for injury prevention in both a primary setting and for children who return to sport after an injury.

\section{Section 2: diagnosis, clinical tests and imaging}

This section addresses the fundamental clinical question: how does the clinician diagnose ACL injury in children? High-quality injury prevention programs are the first-line defence against the potential negative short-term and long-term consequences of ACL injury. However, if injury prevention efforts fail, timely and accurate diagnosis is important, since diagnosis is the starting point for effective management planning and shared decision-making. The clinician combines information from the patient's history, examination and clinical tests, and imaging to build the clinical picture that will inform diagnosis and treatment. Typically, a thorough history and clinical examination will enable the clinician to make an accurate diagnosis.

\section{Clinical pearl 1}

Haemarthrosis (acute swelling in the knee within 24 hours after a trauma due to intra-articular bleeding) following acute knee injury is an important clue suggesting structural knee injury.

\section{Clinical pearl 2}

Diagnosis can be more challenging than in adults because children may be poor historians, they may have greater physiological joint laxity (be sure to examine both knees) and MRI interpretation is more difficult given developmental variants in children. $^{25} 26$

\section{Clinical pearl 3}

Due to the immature skeleton, children may sustain different knee injuries (eg, sleeve fracture of the patella, epiphysiolysis) than adults.

Consider starting the assessment by ordering plain knee radiographs for all paediatric patients with a haemarthrosis/suspected acute knee injury. This is because tibial eminence fractures and an ACL tear can present with a similar history and physical examination findings. It is also important to rule out other paediatric fractures (eg, epiphysial fracture, sleeve fracture of the patella). Perform an MRI to confirm the diagnosis of ACL injury and evaluate other soft tissue structures. ${ }^{27}$ In children with an ACL injury, MRI may yield additional information to identify meniscal tears, other ligament injury or osteochondral injury. In children with a locked knee, an acute MRI is warranted to assess the presence of a displaced bucket handle meniscal tear or an osteochondral injury that may need prompt surgical treatment.

\section{Measurement properties for clinical examination and MRI}

$$
\begin{aligned}
& \text { 'No isolated question, test or image can } \\
& \text { accurately identify an ACL injury, every } \\
& \text { time.' }
\end{aligned}
$$

No isolated question, test or image can accurately identify an ACL injury, every time. The measurement tools available to the clinician are not perfect, but they do yield valuable information in the clinical context. Knowledge of the measurement properties of clinical tools helps the clinician balance the information gained from these tools. The negative predictive values of clinical examination and MRI for ACL tear and meniscal pathology are higher than the positive predictive values (table 1). This means that if the clinical examination and MRI are negative for injury,

\begin{tabular}{|c|c|c|c|c|c|c|c|c|c|c|}
\hline \multirow[b]{2}{*}{ Diagnosis } & \multicolumn{3}{|l|}{ Sensitivity (\%) } & \multicolumn{3}{|l|}{ Specificity (\%) } & \multicolumn{2}{|c|}{ Positive predictive value (\%) } & \multicolumn{2}{|c|}{ Negative predictive value (\%) } \\
\hline & $\begin{array}{l}\text { Clinical } \\
\text { examination }\end{array}$ & MRI & $P$ value & $\begin{array}{l}\text { Clinical } \\
\text { examination }\end{array}$ & MRI & $P$ value & $\begin{array}{l}\text { Clinical } \\
\text { examination }\end{array}$ & MRI & $\begin{array}{l}\text { Clinical } \\
\text { examination }\end{array}$ & MRI \\
\hline $\mathrm{ACL}$ tear & 81.3 & 75.0 & 0.55 & 90.6 & 94.1 & 0.39 & 49.0 & 58.6 & 97.8 & 97.1 \\
\hline Medial meniscus tear & 62.1 & 79.3 & 0.15 & 80.7 & 92.0 & 0.03 & 14.5 & 34.3 & 97.6 & 98.8 \\
\hline Lateral meniscus tear & 50.0 & 66.7 & 0.24 & 89.2 & 82.8 & 0.21 & 34.0 & 30.1 & 94.1 & 95.7 \\
\hline
\end{tabular}
the chance of the patient having an injury is low. However, if the

Table 1 Diagnostic accuracy of clinical examination and MRI in intra-articular knee disorders (adapted from Kocher et al ${ }^{27}$ )

Clinical examination was patient history, physical examination and X-rays performed by a paediatric orthopaedic sports medicine specialist or a postresidency paediatric sports medicine fellow. 


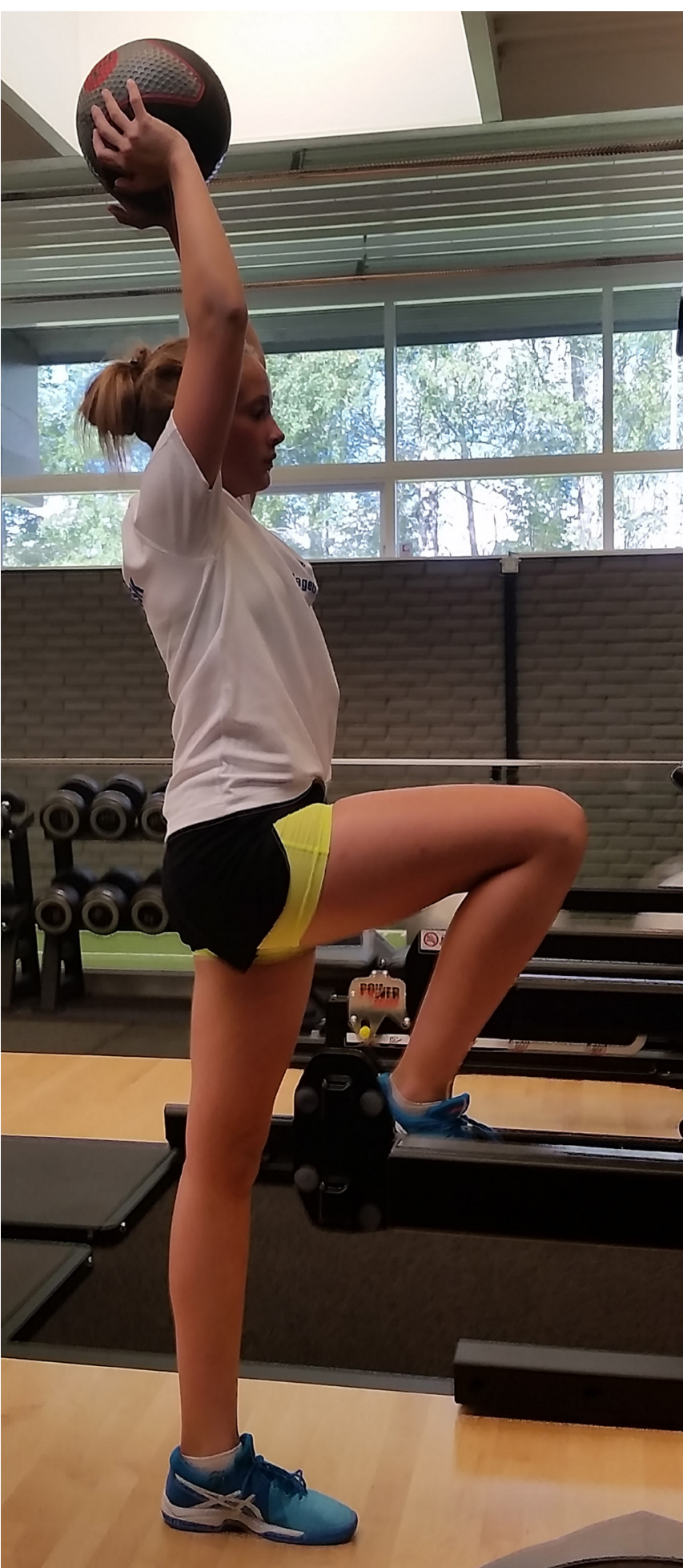

Figure 2 Child demonstrating how to hold terminal knee extension during single limb stance. This is an important marker of quadriceps control in $\mathrm{ACL}$ rehabilitation and prehabilitation.

tests are positive, it does not mean that the clinician can always reliably rule the diagnosis $i n$.

\section{Section 3: treatment of $A C L$ injuries in children}

This section addresses the fundamental clinical question: what are the treatment options for the child with ACL injury? Once the clinician is certain of the injury diagnosis, he or she first needs to know the available treatment options, and discuss these options with the child and the child's parents/guardian, so a shared decision can be made about how best to manage the knee injury.

The goals of treatment for the child with ACL injury are:

1. To restore a stable, well-functioning knee that enables a healthy, active lifestyle across the lifespan.

2. To reduce the impact of existing or the risk of further meniscal or chondral pathology, degenerative joint changes and the need for future surgical intervention.

3. To minimise the risk of growth arrest and femur and tibia deformity.

There are two treatment options that can help the child with ACL injury (with or without associated knee injuries) achieve these goals: high-quality rehabilitation alone (non-surgical treatment) and ACL reconstruction plus high-quality rehabilitation. In this section, the key components of high-quality rehabilitation for the child with ACL injury, and the options for ACL reconstruction surgical technique are described. Potential treatment decision modifiers are outlined in Section 4.

\section{High-quality rehabilitation}

High-quality rehabilitation is a critical component in the management of ACL injury, and the principles of rehabilitation are the same, irrespective of whether the child has had an ACL reconstruction or has elected for non-surgical treatment. Guidance for paediatric rehabilitation is extrapolated from clinical experience and research in adults, although it is uncertain whether adult principles apply to children. ${ }^{28}$ Rehabilitation must be performed in close collaboration with the child's parents/guardians. Exercises and functional goals must be modified, not simply copied from the adult-oriented rehabilitation protocols that may be more familiar to many clinicians. This is because children are not small adults-they cannot be expected to perform unsupervised training independently with perfect technique. Qualified rehabilitation clinicians must supervise rehabilitation for the child with ACL injury.

\section{'Rehabilitation must be performed in close collaboration with the child's parents/ guardians.'}

\section{'Children are not small adults.'}

\section{Rehabilitation focus}

Dynamic, multijoint neuromuscular control is the primary focus of ACL rehabilitation in children. For the youngest patients (with markedly open physes, aged $<12$ years), there is less emphasis on the development of muscular strength and hypertrophy. During maturation, and throughout the onset of puberty, rehabilitation strategies that more closely resemble those used with adult patients are appropriate, due to the increase in androgenic hormones. ${ }^{29}$ These strategies must include heavier and externally loaded strength training.

\section{'Rehabilitation must be thorough, and individualised to the child's physiological and psychological maturity to achieve successful outcomes.'}

Rehabilitation must be thorough, and individualised to the child's physiological and psychological maturity to achieve successful outcomes. Emphasise exercises that facilitate dynamic 
Box 2 Recommended functional tests and return to sport criteria for the child and adolescent with ACL injury

For patients who choose $\mathrm{ACL}$ reconstruction Prehabilitation

- Full active extension and at least 120 degrees active knee flexion

- Little to no effusion

- Ability to hold terminal knee extension during single leg standing (figure 2)

- For adolescents: $90 \%$ limb symmetry on muscle strength tests

For patients who choose ACL reconstruction OR nonsurgical treatment

Phase I to phase II

- Full active knee extension and 120 degrees active knee flexion

- Little to no effusion

- Ability to hold terminal knee extension during single leg standing

Phase II to phase III

- Full knee range of motion

- $80 \%$ limb symmetry on single-leg hop tests, with adequate landing strategies

- Ability to jog for $10 \mathrm{~min}$ with good form and no subsequent effusion

- For adolescents: $80 \%$ limb symmetry on muscle strength tests

Phase III to phase IV: sport participation (return to sport criteria), and continued injury prevention

- Single-leg hop tests: $>90 \%$ of the contralateral limb (with adequate strategy and movement quality)

- Performed gradual increase in sport-specific training without pain and effusion

- Confident in knee function

- Knowledge of high injury-risk knee positioning, and ability to maintain low-risk knee positioning in advanced sport-specific actions

- Mentally ready to return to sport

- For adolescents: $90 \%$ limb symmetry on muscle strength tests

Muscle strength testing should be performed using isokinetic dynamometry or handheld dynamometry/one repetition maximum. The type of test and experience of the tester are highly likely to influence the results. If using handheld dynamometry/one repetition maximum, consider increasing the limb symmetry criterion cut-off by $10 \%$ (ie, $90 \%$ limb symmetry becomes $100 \%$ limb symmetry). Clinicians who do not have access to appropriate strength assessment equipment should consider referring the patient elsewhere for strength evaluation.

lower limb alignment and biomechanically sound movement patterns. Although this has been successfully implemented in rehabilitation programs for adolescents and adults, it has not yet been documented as extensively in children. The exercises are gradually progressed through phases II and III of the paediatric ACL rehabilitation protocol (box 2; online supplementary file 2) as part of sport-specific rehabilitation. See online supplementary file 2 for examples of exercises to consider in each rehabilitation phase. Reinjury anxiety and the patient's confidence in his or her injured knee impact on outcomes after ACL rehabilitation in adults. ${ }^{30} 31$ These psychological factors are also likely to be important in the paediatric population, but currently are insufficiently studied.

Following surgical treatment, the graft type used for ACL reconstruction, and associated injury or surgery to other ligaments, menisci or articular cartilage, necessitate specific adjustments to the rehabilitation program. Rehabilitation programs should be designed to allow the child to participate in his or her team training sessions to maintain the social benefits of staying within the team. Parents or guardians should be active participants in the daily rehabilitation. ${ }^{32}$ This may include assisting the child in technical and functional exercises during team training (eg, short passes in football).

\section{Rehabilitation phases}

Rehabilitation for the child with an ACL injury is organised into four phases (box 2; online supplementary file 2), with an additional prehabilitation phase for those who choose ACL reconstruction. Specific clinical and functional milestones should be met before progressing from one phase to the next. ${ }^{33}$ Throughout the first two phases, the child should be guarded from cutting and pivoting activities during sport, free play and physical education classes in school.

\section{Rehabilitation progression}

The framework for progression through functional milestones is similar for ACL reconstruction and non-surgical treatment. However, there are different expectations for progression and time to return to full participation in sport. For all patients, rehabilitation progression must be guided by clinical and functional milestones (box 2), and return to full participation ${ }^{34}$ is dependent on successfully achieving the return to sport criteria (box 2). Non-surgical treatment should last for at least 3-6 months. ${ }^{35}$ Postoperative rehabilitation should last for a minimum of 9 months before return to full participation in preferred physical activities. ${ }^{36}$

Data from international registries suggest that young athletes are at high risk for a second ACL injury following an ACL reconstruction, ${ }^{37}$ and the risk is highest in the first 12 postoperative months. ${ }^{36} 38$ Therefore, consider advising the child athlete not to return to pivoting sport until at least 12 months following ACL reconstruction. Rehabilitation is also an excellent opportunity to train the uninjured leg, which might be important considering the risk of contralateral injury. ${ }^{38}$ Once the child returns to sport, a comprehensive injury prevention program, emphasising biomechanical alignment and landing/cutting technique should be integrated with usual training.

\section{'Consider advising the child athlete not to return to pivoting sport until at least 12 months following ACL reconstruction.'}

Five considerations when designing rehabilitation programmes for the prepubescent child

Children who are close to skeletal maturity may follow rehabilitation $^{33}$ and return to sport guidelines ${ }^{36}{ }^{39}$ intended for adults. There are five important considerations for the prepubescent child:

1. Consider a home-based program, with emphasis on playful exercises and variation (figure 3 ) to discourage boredom.

2. Single-leg hop tests and isokinetic strength tests have larger measurement errors in the prepubescent population, so use these tests with caution. ${ }^{40}$ 


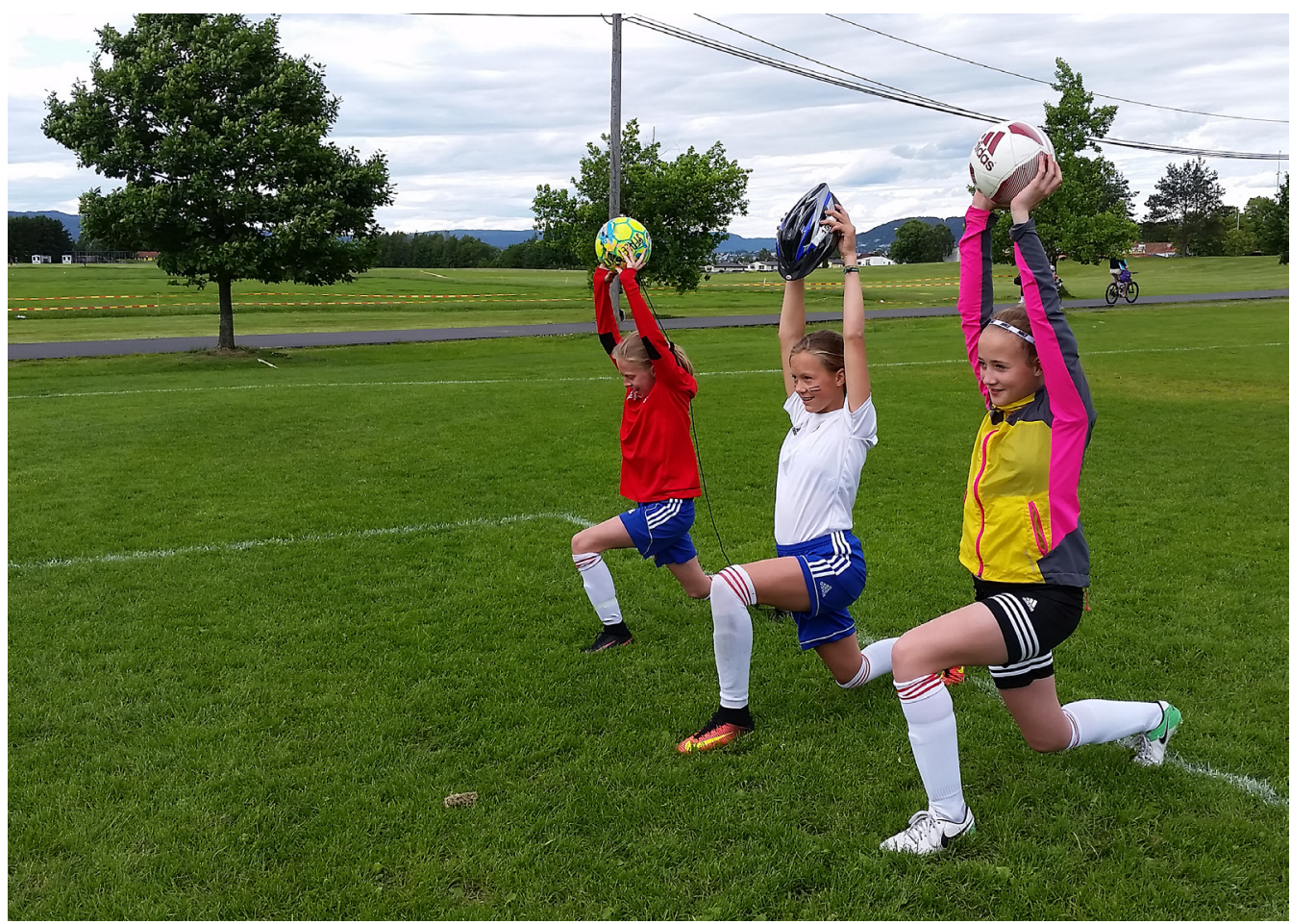

Figure 3 One example of an exercise that could be incorporated into a home-based ACL rehabilitation program.

3. Focus on evaluating the quality of movements during single-leg hop testing, instead of the leg symmetry index measures.

4. Tests and criteria to assess movement quality are yet to be validated, so the responsible clinician needs to have skills and experience in this area.

5. Return to sport criteria were designed and scientifically tested in the skeletally mature patient and are recommended for the child who is close to maturity. ${ }^{36} 41$ The validity of these criteria in the prepubescent child is unknown.

\section{Bracing}

Many clinicians involved in non-surgical treatment of skeletally immature children recommend the child wear a

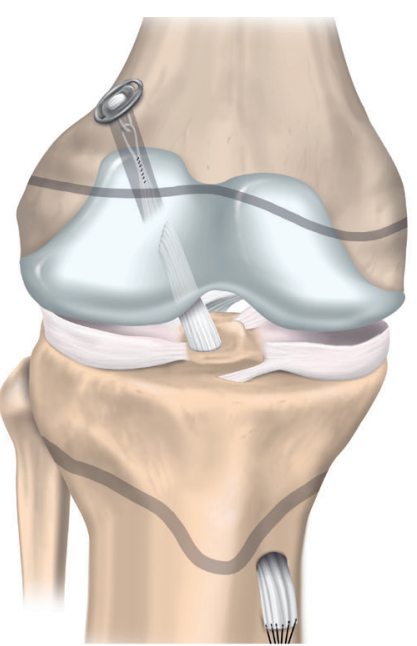

A. Anterior view

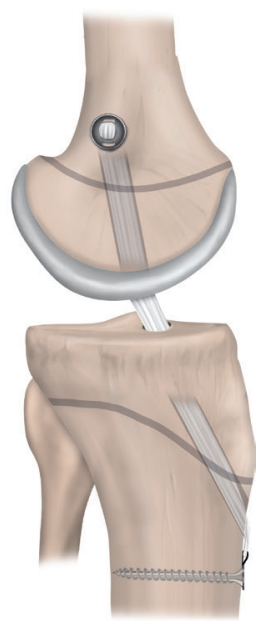

B. Lateral view
Figure 4 Transphyseal ACL reconstruction. (A) Anterior view and (B) lateral view. protective brace during strenuous physical activities. ${ }^{42}$ The child who has had surgical treatment typically wears a brace during the prehabilitation phase, until ACL reconstruction is performed. Following surgery, it is recommended that the child wears a protective knee brace through the successful completion of the functional milestones in rehabilitation phase I (usually 2-6 weeks postoperative, depending on concomitant surgical procedures). However, the effectiveness of bracing following ACL injuries or reconstruction in paediatric patients is unknown. Other considerations related to the use of a brace might be to prevent knee hyperextension or knee valgus/varus, to enhance the child's awareness of his or her injury and as a protective signal to others the child might encounter (eg, at school).

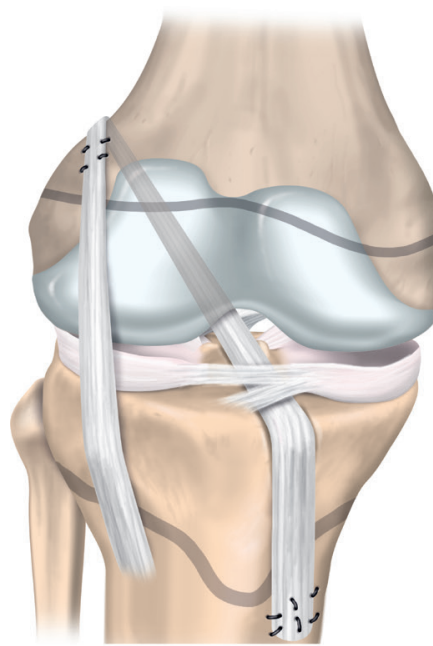

A. Anterior view

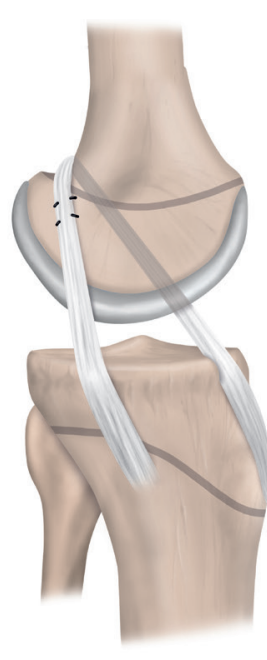

B. Lateral view
Figure 5 Physeal-sparing $A C L$ reconstruction using an over-the-top technique with iliotibial band. (A) Anterior view and (B) lateral view. 


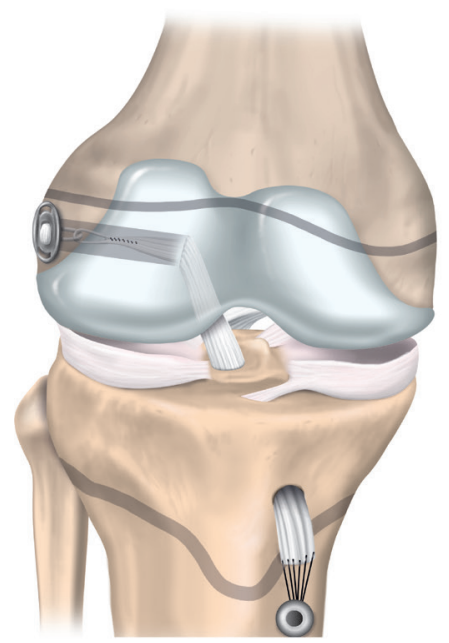

A. Anterior view

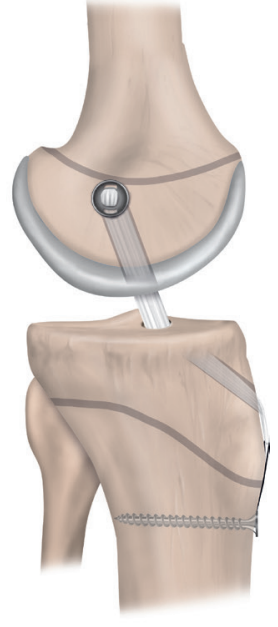

B. Lateral view

Figure 6 Physeal-sparing ACL reconstruction using an all-epiphyseal technique. (A) Anterior view and (B) lateral view.

\section{Surgical techniques}

The general principles of ACL reconstruction in adults also apply to the paediatric patient: use a well-positioned (soft tissue) autograft of adequate size, with adequate fixation to allow functional rehabilitation. Physeal damage should be minimised to avoid growth disturbance. Bone plugs and fixation devices should not cross the physis. ${ }^{43-45}$

Key indications for $\mathrm{ACL}$ reconstruction

There are three indications for paediatric ACL reconstruction:

1. The child has repairable associated injuries that require surgery (eg, bucket-handle meniscus tear, repairable meniscal lesion or osteochondral defect).

2. The child has recurrent, symptomatic knee giving way after completing high-quality rehabilitation.

3. The child experiences unacceptable participation restrictions (ie, an unacceptable modification of activity level to avoid knee giving way).

\section{Box 3 Three different options for femoral tunnel}

\section{trajectories}

Tunnel option A: vertical transphyseal

Advantage: minimises physeal volume affected

Disadvantage: less than ideal coverage of $\mathrm{ACL}$ footprint

Tunnel option B: oblique transphyseal

Advantage: anatomical graft position covering the $\mathrm{ACL}$ footprint

Disadvantage: greater volume of physis negatively affected

\section{Tunnel option C: horizontal all-epiphyseal}

Advantage: appropriate placement at ACL footprint; no drilling through the physis

Disadvantage: requires precise tunnel placement to reduce the risk for physeal damage

There are three possible techniques for paediatric ACL reconstruction.

\section{Transphyseal ACL reconstruction}

The transphyseal technique in the child is similar to the technique the surgeon would use for ACL reconstruction in adults. Single bundle transphyseal ACL reconstruction with a quadrupled hamstring graft is the most common (figure 4). ${ }^{46-51}$ Therefore, because the surgeon is more likely to be familiar with the key elements of the procedure, it may reduce the risk of intraoperative complications. Ensure the diameter of the bone tunnels is as small as possible $(<9 \mathrm{~mm})$ to accommodate an appropriate size graft. ${ }^{52}$ Similarly, to minimise physeal damage, orient the tibial tunnel as vertically and as centrally as possible while maintaining the anatomical position of the graft. On the femoral side, the surgeon should take care to avoid the perichondral ring. Drilling via the anteromedial portal can result in a tunnel that has an elliptical trajectory through the physis. Consider a slightly more vertical orientation than might be used for an ACL reconstruction in an adult patient, or choose a different drilling approach.

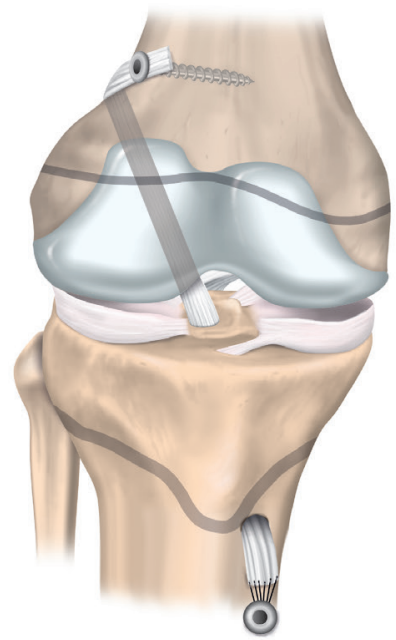

A. Anterior view

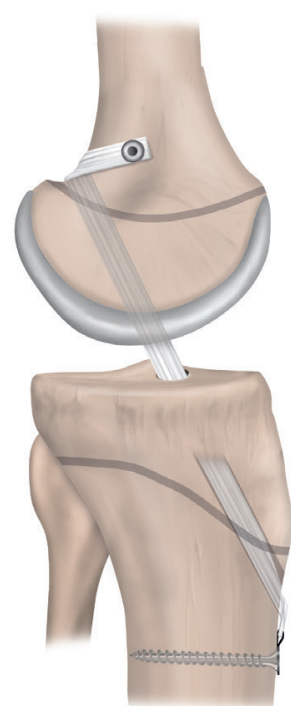

B. Lateral view

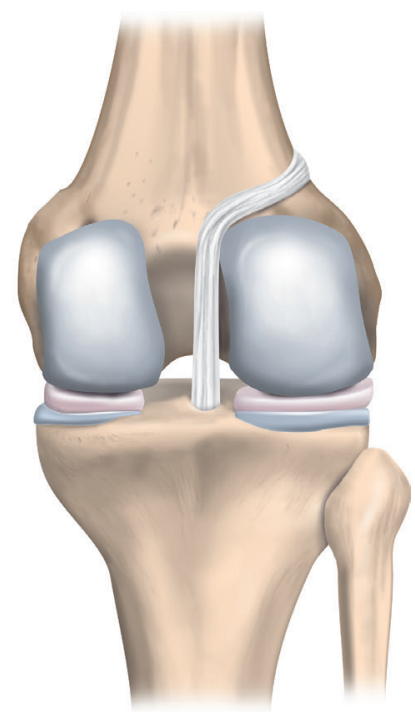

C. Posterior view

Figure 7 Partial transphyseal ACL reconstruction. (A) Anterior view, (B) lateral view and (C) posterior view. 


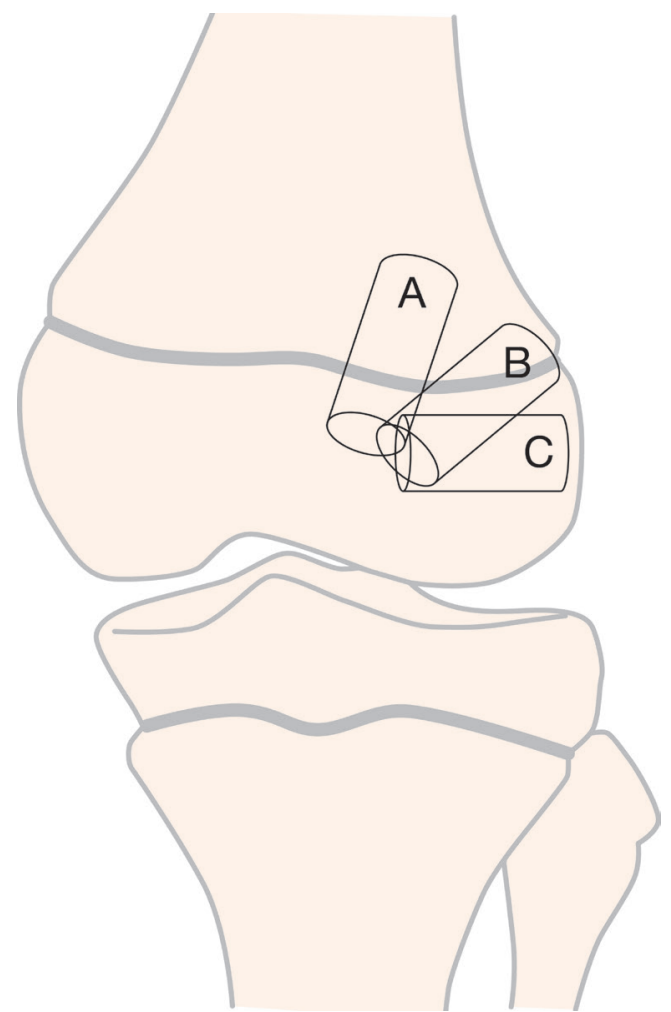

Figure 8 Three different options for femoral tunnel trajectories.

\section{Physeal-sparing $\mathrm{ACL}$ reconstruction}

Physeal-sparing techniques avoid physeal damage in patients with markedly open physes. The techniques include an over-the-top technique with a strip of the iliotibial band (figure 5), ${ }^{53}$ and an all-epiphyseal procedure (figure 6). ${ }^{54}$ In the all-epiphyseal procedures, use fluoroscopic visualisation to reduce the risk of physeal damage. When using the overthe-top technique, avoid femoral rasping to minimise the risk for damage to the perichondral ring.

\section{Partial transphyseal ACL reconstruction}

The partial transphyseal technique (figure 7) combines a transphyseal tibial tunnel with a physeal-sparing technique on the femoral side. ${ }^{55-57}$

\section{Surgical principles and techniques for growth disturbance risk reduction}

Drill hole trajectory and location influence the degree of risk to the physes (box 3 and figure 8). Knowledge of three key principles will help the surgeon minimise the risk to the physes during transphyseal ACL reconstruction:

1. Drilling at the periphery of the physis and the perichondral ring increases the risk of growth disturbance. Drill holes may be placed in an all-epiphyseal manner to allow for drilling at the native ACL footprint, while avoiding the physis. Precise tunnel placement is required when performing this technique to avoid damage to the undulating distal femoral physis.

2. Bone tunnel drill holes should be as vertical as possible (while still maintaining anatomic graft position) and as central as possible. This is especially important when drilling through the anteromedial portal. Drilling an oblique tunnel rather than a more vertical tunnel increases the amount of physis removed and increases the risk for growth disturbance.
3. Do not cross the epiphysis with hardware, implants or bone blocks. Fill bone tunnels with soft tissue, rather than leaving the tunnels open.

\section{Graft choice and fixation}

Only soft tissue grafts (not allografts) should be used for ACL reconstruction in paediatric patients with open physes. The quadrupled hamstring graft is most common. ${ }^{47-51} \mathrm{~A}$ quadriceps tendon graft may be used. ${ }^{56}$ The patella tendon should not be harvested in paediatric patients with open physes to avoid damage to the tibial tubercle apophysis. Allografts are not indicated in paediatric patients in most cases, since the use of allografts in paediatric ACL reconstruction has poor clinical outcomes. $^{58-60}$

\section{'The use of allografts in paediatric ACL reconstruction has poor clinical outcomes.'}

A novel technique involving the use of living-donor hamstring tendon allograft has been reported ${ }^{49} 61$ to avoid the varied sterilisation techniques used in cadaveric soft-tissue allografts, and preserve of the neuromuscular unit of the growing patient. ${ }^{62} 63$ However, long-term clinical outcomes are yet to be assessed.

Extracortical fixation of soft tissue grafts may be performed with a cortical button, suture, post or staple. Aperture fixation may be performed with interference screws, provided the screws do not cross the physis.

\section{Graft incorporation}

Data regarding ACL graft incorporation in children are scarce. Paediatric soft tissues have a greater biological growth potential compared with adults, ${ }^{6465}$ and cell migration and proliferation of ACL-fibroblasts slows as the person grows older. ${ }^{66}$ The clinical relevance of the growth potential to paediatric ACL reconstruction is still unclear, ${ }^{67}$ although there is a rationale from animal models that the paediatric ACL graft may remodel faster than the adult ACL graft. ${ }^{68}$

\section{Adaptations and remodelling in the growing child}

The ACL graft must adapt as the child grows. The graft may increase in length as the bone grows, and the bone tunnels may reduce in relative size. ${ }^{6970}$ It is uncertain whether the diameter of the intra-articular part of the graft becomes longer and thinner, ${ }^{71}$ or not, ${ }^{70}$ as the child grows. The graft does not increase diameter as the child grows, but may increase in length. ${ }^{72}$

With longitudinal bone growth after transphyseal ACL reconstruction, the graft may become more vertically oriented. This observation might be explained by the movement of the femoral fixation site with physeal growth or because the tibial tunnel aperture becomes relatively more posterior due to greater anterior growth of the proximal tibia. Other changes occurring as the child grows are secondary intercondylar notch narrowing, distal migration of the tibial and/or proximal migration of the femoral extracortical fixations and verticalisation of the Blumensaat line. ${ }^{73}$ However, the long-term clinical significance of these growth-related changes is unclear.

\section{Section 4: treatment decision modifiers}

This section addresses the fundamental clinical question: what are the most important considerations when making treatment decisions? The key issues addressed relate to assessment of skeletal maturity, the decision for surgery or not, management of injuries to other knee structures and potential adverse events 
following treatment. These issues may alter the ACL injury management decision, depending on the decision-making team's (which should include clinicians, the child and the child's parent/ guardian(s)) risk tolerance.

\section{Skeletal age assessment}

Assessing and documenting the child's skeletal age, in addition to his or her chronological age, is necessary to individualising treatment of ACL injuries. The main goal with respect to skeletal age assessment is to define remaining knee growth. Protecting the physis and perichondral ring from damage during ACL reconstruction is an important consideration ${ }^{45}$ — an insult to a growth area that is near completion of growth can result in premature closure.

\section{'Estimating skeletal age and remaining growth are key considerations for treatment decision-making.'}

Estimating skeletal age and remaining growth are key considerations for treatment decision-making. These estimates will guide choice of treatment, timing of surgery and surgical method. Open physes in the child are vulnerable at surgery, and none of the current recommended surgical treatments for the child with an ACL injury can be guaranteed to protect the physis and avoid the potential complication of growth arrest or deformity (these risks are outlined below). The clinician might also consider long leg radiographs (hips to ankles) after injury to establish a baseline for assessing the potential development of angular deformity and leg length discrepancy. Assessing skeletal age is also relevant in research and may be beneficial for medicolegal reasons. If overgrowth, growth arrest or deformity occurs, presurgical documentation of skeletal age may be important (box 4).

\section{Treating the child with ACL injury: to operate or not to operate?}

Children who have repairable additional injuries at ACL injury diagnosis (eg, displaced bucket-handle meniscal tear) should be treated with early ACL reconstruction and meniscal repair. ${ }^{77}$ In those without additional injuries warranting surgery, there are conflicting opinions regarding the best treatment approach. These approaches range from early ACL reconstruction for all

\section{Box 4 Five considerations for skeletal age assessment}

1. Understand the difference between skeletal age and chronological age.

2. Use imaging of the knee to determine if the femoral and tibial physes, and the tibial tubercle apophysis are open. If the growth areas are closed, then, independent of chronological age, the child can be treated as an adult.

3. None of the specific methods for skeletal age determination in isolation is sufficient to accurately determine skeletal age.

4. Use a multifaceted clinical approach to determine skeletal age that includes whether or not the child has had an adolescent growth spurt, the relative heights of the child's parents and Tanner staging. ${ }^{74}$

5. The most common method of skeletal age assessment is via posterior-anterior left hand and wrist $\mathrm{X}$-ray. This can be compared with a skeletal atlas (eg, Gilsanz and Ratib ${ }^{75}$ or Greulich and Pyle ${ }^{76}$ ) or using a smart-phone application (eg, the Bone Age app for iPhone). children, to primary non-surgical management (high-quality rehabilitation alone) with the option of late ACL reconstruction if the child has recurrent instability problems despite high-quality rehabilitation or if he or she sustains secondary intra-articular injuries.

A well-performed ACL reconstruction and preservation of the meniscus can restore knee stability ${ }^{78}$ However, if the child receives inadequate (or no) rehabilitation, the chances of recovering high-level function to safely participate in all aspects of life (including pivoting sports), for the rest of his or her life, might be slim. Similarly, high-quality rehabilitation will not salvage poor surgical treatment (eg, graft malposition).

Children who undergo ACL reconstruction after failed non-surgical management may have a higher number of meniscal and chondral injuries at the time of ACL reconstruction compared with those who undergo early ACL reconstruction. ${ }^{79-81}$ The number of instability episodes prior to surgery appears to be a more important factor than the length of time between injury and surgery. ${ }^{82}$ This consideration is the background for early surgery decisions. However, there are a lack of high-quality, prospective studies investigating the outcomes of surgical and non-surgical treatment for paediatric ACL tears. ${ }^{4}$

\section{'Non-surgical treatment is a viable and safe option in skeletally immature patients who do not have associated injuries or major instability problems.'}

Non-surgical treatment is a viable and safe treatment option in skeletally immature patients who do not have associated injuries or major instability problems. ${ }^{83}$ High-quality rehabilitation alone may stabilise the knee dynamically without compromising the physes, and is a focused training program supervised by a qualified rehabilitation clinician (see Section 3 for the key principles of high-quality rehabilitation). Non-surgical treatment can be a permanent treatment option for those who do not develop functional instability, or a short-term option to delay ACL reconstruction until the child has reached skeletal maturity. Abandoning non-surgical treatment in favour of ACL reconstruction is an option if the child has recurrent instability problems despite completing high-quality rehabilitation, or if the child has a secondary intra-articular injury. Therefore, clinicians must work together to closely and frequently monitor the child with repeated MRI and clinical examination as appropriate, being alert to instability episodes and secondary injuries that require prompt assessment and treatment. ${ }^{82}$

\section{Risks associated with $\mathrm{ACL}$ reconstruction}

Irrespective of the technique, surgical treatment of the ACL has inherent risks. Different ACL reconstruction techniques have different considerations to help avoid risk to the physes, articular surface and soft tissue structures of the knee. Here, we describe five key risks associated with surgical treatment for ACL injury of which clinicians, patients and their parents/guardians must be aware.

\section{Risk 1: growth disturbance}

Growth disturbances are a rare (approximately $2 \%)^{43}$ but serious risk of ACL reconstruction. Growth disturbances may be a result of hardware, bone plugs at the physis, extra-articular tenodesis or use of over-the-top femoral position. Most of the growth in the child's lower extremities occurs from the physes of the distal femur and proximal tibia. Any surgical 
procedures where tunnels are drilled through or near the physis are associated with a risk of growth arrest, and associated angular deformity and/or leg length discrepancy. Transphyseal techniques have a higher rate of graft rupture and a lower rate of lower limb deformity or axis deviation. Physeal-sparing techniques have a lower rate of graft rupture, and a higher rate of lower limb deformity or axis deviation.

Highly tensioned soft tissue grafts placed across femoral physes have been associated with limb length discrepancy and angular deformity. ${ }^{84}$ Metaphyseal fixation techniques may pose an increased risk of femoral angulation and rotation relative to other techniques. Epiphyseal techniques may increase the risk of rotational deformity and decrease the risk of angular deformity. ${ }^{85}$ Excessive growth may also be a problem, including symmetrical and asymmetrical overgrowth. ${ }^{86}$

Most patients with ACL rupture requiring surgical treatment are approaching skeletal maturity, and do not have substantial growth remaining. This means that angular deformities and limb length discrepancies are likely of relatively low clinical significance. Therefore, it may be reasonable to perform transphyseal procedures when the child has minimal growth remaining.

\section{Regularly monitor the patient until skeletal maturity}

Routine clinical and radiological follow-up within the first 12 postoperative months can help the surgeon detect early clinical and radiographic evidence of leg length discrepancy, angular deformity or and physeal injury. For the child with markedly open physes, appropriate follow-up evaluation of leg length discrepancy might include annual clinical assessment and knee radiographs with long-leg alignment views until skeletal maturity and physeal closure. Height should be monitored, and if growth exceeds $6 \mathrm{~cm}$ in 6 months, or if clinical findings warrant, the annual assessment should be brought forward.

\section{Classifying growth disturbances}

Growth disturbances can occur in several different forms (figure 9). The growth arrest may be due to:

- Localised physis injury resulting in a bone bridge leading to growth arrest and possible malalignment (type A);

- Overgrowth process potentially caused by hypervascularisation (type B);

- Undergrowth process arising from a graft traversing a physis under tension during growth and leading to a tethering effect (type C).

\section{Risk 2: secondary ACL rupture}

Young age, returning to pivoting sport and receiving an allograft are important predictors of new ACL injury after index ACL reconstruction..$^{58} 87$ One in four patients under 25 years who returned to pivoting sports after ACL reconstruction can be expected to sustain a new ACL injury (the pooled ipsilateral reinjury rate is approximately $10 \%$; the pooled contralateral reinjury rate is approximately $12 \%){ }^{88}$

High rates of reinjury among young people with ACL reconstruction are concerning, although data regarding reinjuries among children with ACL reconstruction are sparse in comparison to data from skeletally mature patients. The best available evidence suggests a graft rupture rate in children and adolescents (age range 6-19 years) of 13\%, and a contralateral ACL injury rate of $14 \% .{ }^{89}$ It is reasonable to hypothesise that high-quality rehabilitation with high adherence is likely an important step in reducing reinjury risk. The principles of rehabilitation for the skeletally immature patient are addressed in Section 3. The ACL graft is also affected by the status of the other ligaments, menisci, cartilage surfaces, limb alignment, rotation and the dynamic muscle control of these structures-all factors that must be considered during treatment decision-making.

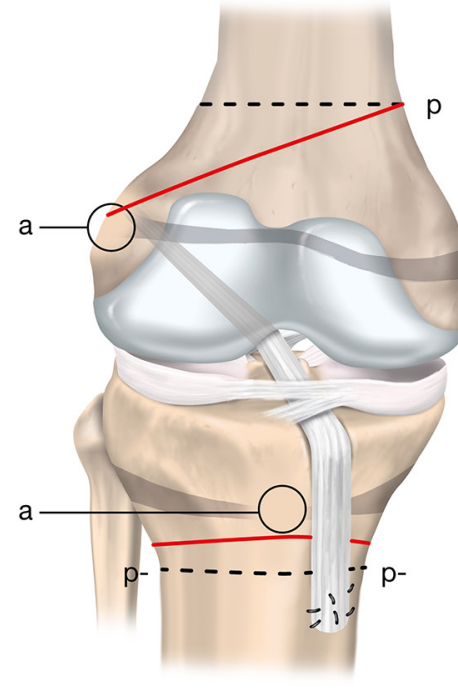

a

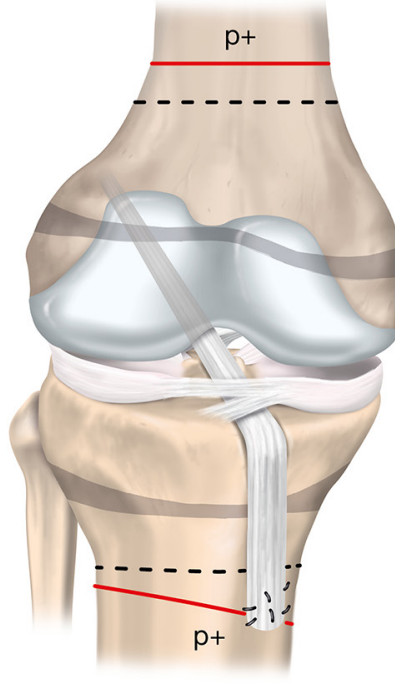

b

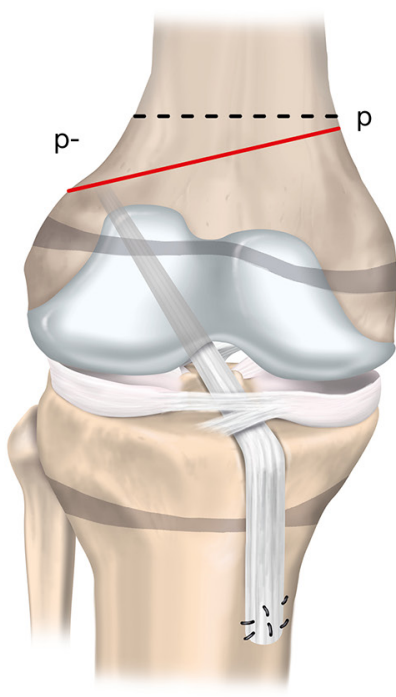

C

Figure 9 Three growth disturbances that may occur following ACL reconstruction. ' $p$ ' represents the physiological growth process; dashed lines represent the physiological growth arrest lines; continuous lines represent the observed pathological growth arrest line. Type A (arrest): growth arrest process (a) occurs after a localised injury to the physis and results in a bone bridge across the physis. The extent of deformity is proportional to the location and size of the initial physeal injury. Type B (boost): overgrowth process (indicated by $\mathrm{p}+$ ) is probably caused by local hypervascularisation, stimulating the open physis (b). This growth disturbance is temporary and usually becomes apparent in a limited period of 2 years following $\mathrm{ACL}$ reconstruction. It primarily leads to leg length discrepancy. Type $C$ (decelerate): undergrowth process (indicated by $p-$ ) due to a tenoepiphysiodesis effect (c). The graft tension across the open physis causes the deformity. Adapted from Chotel et al. ${ }^{86}$ 
Risk 3: poor long-term knee health

Meniscectomy is associated with an increased risk for osteoarthritis. $^{90-92}$ Therefore, wherever possible, treatment of ACL injuries must emphasise preservation of the meniscus. Prior meniscectomy at the time of ACL reconstruction is associated with higher likelihood of chondral lesions, while prior meniscal repair is not associated with a higher likelihood of chondral lesions. ${ }^{93}$ Because of the technical nature of performing ACL and concurrent meniscal surgery in smaller, younger patients with open physes, patients in whom meniscus repair is indicated should be treated by surgeons who (1) are experienced in treating patients with open physes and (2) perform a high volume of meniscal repairs.

\section{Risk 4: knee stiffness}

Knee stiffness may be due to the degree of injury to the ACL, disruption of the joint capsule and injury to structures other than the ACL. Knee stiffness may also be related to surgical interventions or inadequate rehabilitation. Knee stiffness is rare in children aged 13 years and younger, and less common in males and in those having surgery with an iliotibial band or hamstring autograft. ${ }^{94}$ Patients who have knee stiffness following ACL injury should aim for full active knee extension range of motion prior to undergoing ACL reconstruction. If the knee extension deficit persists beyond 3 months postoperative, MRI to assess for anterior impingement (cyclops lesion) and subsequent arthroscopy (should the deficit continue to be unresolved despite focused rehabilitation attention) may be warranted.

\section{Risk 5: infection}

Data related to infection risks for paediatric patients are extrapolated from literature that combines paediatric and adult patients. Infection rates in adult patients are generally low for ACL reconstruction. The rate of deep infections after ACL reconstruction with autograft is $0.19 \% .^{95}$

\section{Management of associated injuries}

Here we address the key issues for managing cartilage and meniscal injuries in combination with ACL rupture, and the multiligament-injured knee.

\section{Associated meniscus and cartilage injuries in children with $\mathrm{ACL}$ injuries}

The degree of vascular penetration of the menisci declines with age, with between $10 \%$ and $30 \%$ of the menisci receiving vascular inflow in adults. ${ }^{96}$ The more robust vascular distribution in the paediatric menisci is reflected by increased intrameniscal signal intensity on MRI. Globular and intrameniscal signal may be observed in children and may appear to be an intrasubstance meniscal tear. However, these findings are benign, and usually reflect the abundant vascularity of the paediatric menisci (figure 10). ${ }^{97}$

It is important to evaluate the MRI characteristics of the paediatric menisci to rule out meniscal injuries. In cases where the diagnosis is difficult, a diagnostic arthroscopy may be performed to clarify the diagnosis and ascertain the state of the meniscus. The clinician should also assess for a posterior medial meniscocapsular tear (ramp lesion).

\section{'The clinician should also assess for a posterior medial meniscocapsular tear (ramp lesion).'}

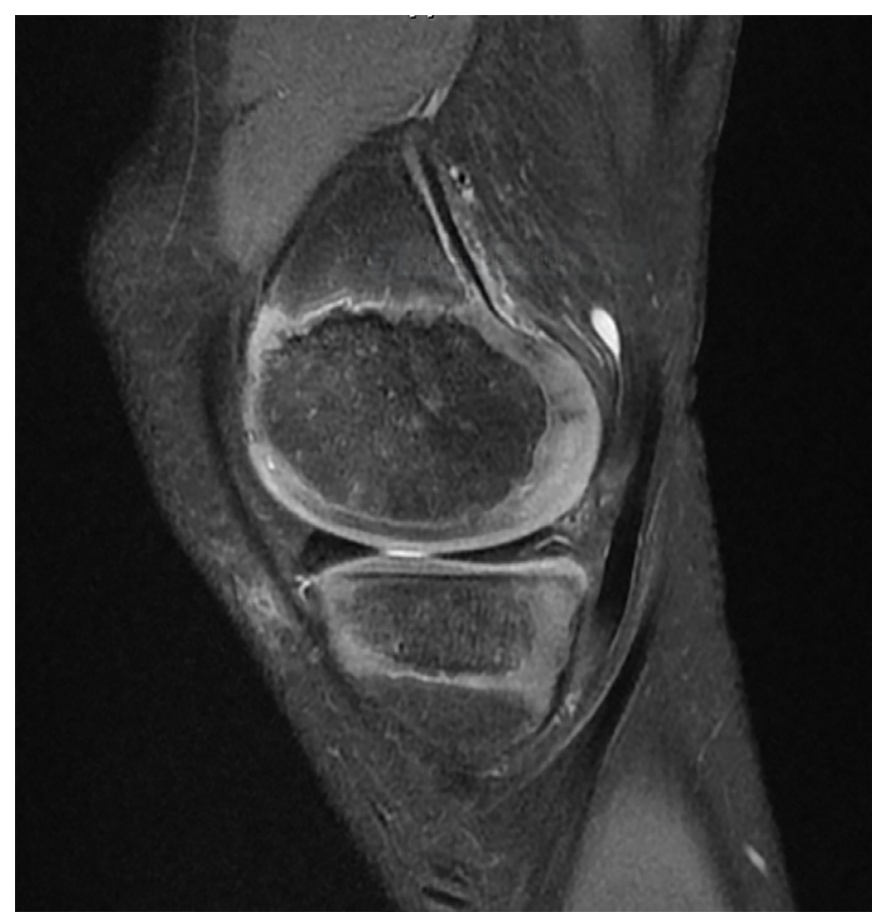

Figure 10 Appearance of the highly vascular paediatric meniscus of a boy aged 10 years on 3.0 T MRI (Signa HDxt 3.0T; GE Medical Systems).

Ramp lesions may be present in one in six adult patients with ACL injury, and the prevalence of ramp lesions in children with an ACL injury is similar to adults. ${ }^{98}$ The surgeon should be vigilant to verify the presence or absence of a medial meniscal ramp tear by visualising the posteromedial compartment. Use a posteromedial knee arthroscopic portal, if necessary, to probe the posteromedial meniscocapsular junction. Ramp lesions may place more stress on an ACL reconstruction if the lesion is not concurrently repaired. ${ }^{99}$

\section{'Meniscal repair should be performed whenever possible,}

Meniscal repair should be performed whenever possible in the paediatric patient because of the deleterious effects of meniscectomy and the positive outcomes of meniscal repair (ie, the improved healing potential of the meniscus). ${ }^{79} 100101$ This is especially important for bucket-handle, root and radial meniscal tears and ramp lesions. If the surgeon does not have the skills or equipment to repair the meniscus tear, he or she should consider referring to a surgeon who has the expertise and equipment. Early diagnosis and appropriate treatment of ACL injuries and meniscus tears is needed to provide the best chance of preserving meniscal tissue.

Articular cartilage injuries in combination with ACL injury are less common than meniscal tears. ${ }^{79}$ However, the clinician should have a higher degree of suspicion of articular cartilage injury in patients with combined ACL and meniscal injuries. ${ }^{102}$ The medial femoral condyle may be particularly vulnerable. ${ }^{102}$ Factors that may be associated with more severe chondral lesions are recurrent instability episodes and increased time between ACL injury and reconstruction. ${ }^{80} 102103$ It is unclear whether non-surgical management of ACL injuries is associated with a higher incidence of new chondral and meniscal lesions than ACL reconstruction. ${ }^{104}$ 
Associated ligament injuries in children with $\mathrm{ACL}$ injuries

There is limited research on multiligament knee injuries and treatment in paediatric patients, and these injuries are less common in children than in adults. ${ }^{105}$ Therefore, consider referral to a specialist centre.

\section{Specific surgical treatment considerations}

Combined $A C L$ and fibular collateral ligament injuries

Use fluoroscopy prior to placing suture anchors for a repair, or for tunnel reaming for a concurrent ligament reconstruction, to evaluate tunnel position in relation to the physes. ${ }^{106}$

\section{Combined ACL and posterior cruciate ligament injuries}

Non-surgical treatment may be appropriate for partial posterior cruciate ligament (PCL) tears or non-displaced avulsion injuries. PCL reconstruction is a relatively safe and viable treatment option in patients with multiligament injuries. ${ }^{107}$ Using a tibial inlay technique with a modified femoral tunnel location avoids transphyseal drilling, ${ }^{108}$ although there are no high-quality studies of this technique in children.

\section{True knee dislocation}

Perform a reduction by manipulating the tibia relative to the femur. Avoid forceful hypertension or rotation, to minimise the risk for damage to cartilaginous and/or neurovascular structures. Following reduction, a dynamic knee brace can be applied (for at least 12 weeks) to prevent further intra-articular damage and to help hold the knee reduced ${ }^{109}$ while further treatment is planned. Ultimately, reconstruction of the ACL and PCL in combination with repair/reconstruction of additional ligaments (as needed) is the appropriate treatment.

\section{Section 5: paediatric patient-reported outcome measures}

This section addresses the fundamental clinical question: how does the clinician measure outcomes that are relevant to the child with an ACL injury? Assessing patient-reported outcome measures (PROMs) provides insights into aspects of the patient's function that cannot be evaluated with clinical tests or imaging. ${ }^{110}$ Because of this, evaluating PROMs is important when managing the child with an ACL injury, and when conducting research in this field.

Valid outcome instruments must have appropriate measurement properties, including reliability, validity (content, criterion and construct) and responsiveness. Instruments that were developed for adults may not be valid for children and adolescents. Paediatric patients have different levels of comprehension (this age group includes a spectrum of comprehension abilities from younger children to older adolescents) and interpretation of instruments. Most importantly, paediatric patients may value different outcomes when evaluating their knee function, and instruments must reflect the issues that are important to children and adolescents.

Paediatric PROMs should be either developed or specifically validated in this population. The process of validation should include an assessment of comprehensibility, reliability, validity and responsiveness. Child-reported outcome assessment is typically valid in older children and adolescents (aged $>10$ years). ${ }^{111}$ In younger children (aged $<10$ years), parent-proxy-reported outcome assessment may be more appropriate. However, there is potential for bias with proxy-reported outcomes. ${ }^{112}$

Paediatric PROMs (table 2) must be valid for children and adolescents with ACL injury. However, a paediatric-derived PROM is not currently available. Such an instrument would
Table 2 Summary of appropriate PROMs for the child with ACL injury

\begin{tabular}{|c|c|}
\hline Type of instrument & Scale \\
\hline Health-related quality of life & $\begin{array}{l}\text { Child Health Questionnaire } \\
\text { PedsQL } \\
\text { Pediatric PROMIS }\end{array}$ \\
\hline $\begin{array}{l}\text { Condition-specific or region- } \\
\text { specific }\end{array}$ & $\begin{array}{l}\text { Pedi-IKDC }{ }^{131} \\
\text { KOOS-Child }\end{array}$ \\
\hline Activity level assessment & Pediatric Functional Activity Brief Scale $\mathrm{e}^{133}$ \\
\hline
\end{tabular}

ensure the items covered issues that matter most to children and adolescents. The Pedi-IKDC and KOOS-Child were adapted from adult PROMs designed to assess self-reported knee function. The Pedi-IKDC has been correlated to the International Knee Documentation Committee subjective knee formproviding preliminary evidence of construct validity. ${ }^{10} 11$ Given that patients with a history of ACL injury may develop symptoms and signs of osteoarthritis within 10 years of the index injury, ${ }^{5}$ and the relationship between symptomatic osteoarthritis and poor quality of life, ${ }^{3}$ assessing quality of life and long-term knee function outcomes using valid PROMs may also be important.

Recommendations for using PROMs in clinical practice with paediatric patients:

- Use a generic measure of health-related quality of life;

- Use either the Pedi-IKDC or KOOS-Child to assess self-reported knee function;

- Use the Pediatric Functional Activity Brief Scale to assess self-reported activity level.

In research, it may be appropriate to include other PROMs depending on the research question. Researchers need to make decisions about the most appropriate outcome(s) when planning their study.

\section{Section 6: ethical considerations}

This section addresses the fundamental clinical question: what are the clinician's role and responsibilities? Treatment decisions that involve children are among the most difficult decisions the clinician faces, especially when scientific knowledge is limited. Striking a balance between ethical principles can be especially challenging when there is a conflict of opinion. In this section, we outline the relevant ethical considerations for the clinician who treats children with ACL injuries.

It is impossible to provide specific ethical guidance that applies to all sporting injuries in adolescents and children, given the varying individual circumstances. However, it is incontrovertible that it is in the best interests of all children not to have knee and associated injuries. Therefore, injury prevention programs are fundamental to the best interests of the child. Clinicians have an obligation to support policies and practices that encourage coaches, teams/clubs and (inter)national federations to prioritise injury prevention. All parties should be committed to protecting the long-term welfare of the growing child. Nevertheless, there may be exceptional cases where parents/guardians may, with the approval of their child, rationally prioritise short-term goals. One example could be that, despite inherent risks for reinjury, an early return to sport might be a high priority for a child who has exceptional talent in a given sport.

Protecting the integrity of the knee should be the clinician's primary focus. Decisions regarding how to protect the integrity of the child's knee must be shared between the child, parent/ guardian (surrogate decision maker) and clinician. ${ }^{113}$ Parents have an obligation to care for their children, and bring them up 
to live good lives. ${ }^{114}$ Nevertheless, parents have different perceptions of what constitutes 'good living'. ${ }^{115}$ Most ethicists agree that parental influence is a positive thing. ${ }^{116}$ However, in high performance children's sport, parents and coaches can pressure the child and clinician to focus on short-term athletic goals at the expense of long-term welfare. ${ }^{117}$

Issues related to consent and obtaining consent for treatment Children are a vulnerable population. ${ }^{118} 119$ In the context of treatment of ACL injury, the child is doubly vulnerable given his or her developing, but uncertain, life plans ${ }^{120}$ and developmental stage. We can never be certain of all of the risks to normal development of the individual child. ${ }^{121}$ It is difficult to gain legally legitimate informed consent from children in the treatment decision-making process. Therefore, the clinician needs to act as a cofiduciary on behalf of the child, while parents give consent. ${ }^{122}$

The clinician and/or parent(s) are obliged to serve the interests of the child above all other interests. ${ }^{122} 123$ This is what is meant by having a fiduciary duty to the patient. The clinician must talk with both the child and the surrogate decision makers in ways that are respectful of, and comprehensible by everyone involved. ${ }^{124}$ In addition to avoiding conflicts of interest, the clinician must always seek the approval or assent of the child, irrespective of the parents/guardians wishes, at a communication level that matches the child's competence. ${ }^{125}$ The child should be present in all discussions concerning him or her, to respect his or her (emerging) autonomy. ${ }^{126}$

\section{Arriving at a shared decision}

There should be consensus between all parties when arriving at a decision. This consensus should be based on realistic assessments of risks and benefits and a proper consideration of the goals of the child and parent. The clinician's responsibility is to guide this discussion with accurate information from the best quality research. There are several ethical standards that can help the clinician, child and parent(s) navigate the decision-making process, and arrive at ethically justified treatment decisions.

Some paediatric ethical standards are not identical-some aim at higher thresholds, while others accept a lower threshold of justification. There are six standards that can be helpful in different clinical scenarios in paediatric ACL injury (box 5).

Box 5 Six standards that can be helpful in different clinical scenarios in paediatric ACL injury

1. Best interests ${ }^{134}$ : widely used, but it is difficult to predict what is in the best long-term interests of a child.

2. Harm principle ${ }^{135}:$ a threshold below which the clinician should not acquiesce to parent-led decision, so that the child is not harmed.

3. Parental discretion ${ }^{136137}$ : parent-preference is accepted because it is not sufficiently harmful to the child for the clinician to dissent from the parent( $\left.\mathrm{s}^{\prime}\right)$ choice.

4. Costs/benefits ${ }^{138}$ : involves risk assessment, but its application to the child means that the clinician may need to compare very different kinds of futures that may or may not eventuate.

5. Not unreasonable ${ }^{139}$ : focuses only on the appropriateness of decisions and decision maker(s).

6. Reasonable choice ${ }^{140}$ : a decision method that attempts to incorporate the previous five standards into a single model or intervention.
The clinician has an important role in treatment decision-making, because he or she typically has superior knowledge of treatment options, risk and benefits than children and parents. To best guide the child and his or her parent(s), the clinician must have a clear idea of the range of interventions that are (1) optimal, (2) acceptable and (3) not desirable, and be able to justify this with reference to the best quality research and clinical experience. In many healthcare settings, parent(s) take responsibility for the ACL treatment decision, commensurate with the child's assent. Where there is a lack of consensus in the decision-making process (eg, the parent decides for something that is not recommended by the clinician), the clinician may also consider whether he or she can defend a treatment recommendation based on one of the six ethical standards.

\section{Section 7: future research}

Management of paediatric ACL injuries is strongly debated. Reflecting some of the concern and controversy is a high ratio of clinical commentaries and narrative reviews to original articles on this topic. The problem for the clinician is that there is scarce high-quality evidence that he or she can look to, to help him or her best manage paediatric ACL injuries. The scientific literature is inconsistent and limited by inferior methods that carry a high risk of bias. ${ }^{4127}$ There are no randomised trials comparing different treatment approaches or different surgical techniques. Most of the publications have only short-term follow-up; there are none with follow-up beyond 10 years. Therefore, long term knee-health (including osteoarthritis) and quality of life is unknown.

\section{METHODOLOGICAL CONSIDERATIONS}

There are five key issues that must be addressed by future studies:

1. Most clinical studies on paediatric ACL injury are of crosssectional or retrospective design, the study populations are often at high risk of selection bias and include small samples. This means there is a high risk that existing research does not reflect the typical paediatric patient with an ACL injury.

2. Many studies do not provide adequate descriptions of the treatments that the patients have received, and patient adherence has not been reported. A meaningful interpretation of study outcomes is only possible with a detailed description of the surgical technique, rehabilitation, brace usage, return to sport clearance and recommendations of activity modification.

3. Many studies fail to assess the skeletal age of included participants, and few report the remaining growth of participants. Chronological age alone is an unreliable indicator of skeletal maturity. Because of this, it is difficult to know to which skeletal age group these research results apply.

4. Patients aged up to 18 years are often included in paediatric studies. This is a problem because it is likely that the patient population is a mix of skeletally mature and immature patients. Therefore, the literature may be biased towards the older patients. Having mixed populations also complicates pooling or comparing results from skeletally immature patients across studies.

5. Knowledge of preinjury and post-treatment activity level gives important insight into a key risk factor for injury. The greater exposure a child has to potentially injurious situations (eg, playing pivoting sport), the greater the chance of (re)injury. Activity level is a key confounding factor that is 
rarely accounted for in statistical analyses. This means there is a risk that estimates of secondary injury incidence may be overestimated or underestimated in comparisons between studies or patient-groups.

\section{RESEARCH PRIORITIES}

There are four research priority areas to improve prevention and outcomes of paediatric ACL injury:

1. Prospective injury surveillance studies to identify injury mechanisms and modifiable risk factors for ACL injury, combined injuries and knee reinjuries.

2. Prospective research on outcomes after surgical and non-surgical treatment. Long-term follow-up (beyond 10 years) is essential to answer key questions of how an ACL injury in childhood impacts physical activity, future knee-health and quality of life.

3. Research on the efficacy of different surgical techniques and characteristics (eg, timing of surgery, graft types), and highquality rehabilitation programmes, knee brace usage and activity modification after injury and surgery.

4. Multicentre and registry studies should be prioritised. Because of smaller numbers of ACL injuries in paediatric patients than in skeletally mature patients, specialist treatment centres, expert clinicians and researchers must prioritise collaboration.

\section{IN MEMORY OF DR ALLEN F ANDERSON}

An excellent clinician-scientist and a keen coworker in this project, Allen F Anderson, MD, died in a farming accident on Sunday, 12 November 2017. This tragedy occurred shortly after he had been an active participant in this IOC consensus meeting on the topic of his life-long clinical and research passion, paediatric ACL injuries.

Born on 16 November 1949, Dr Anderson was a graduate of the University of Tennessee College of Medicine. He completed a residency in orthopaedics at Vanderbilt University and was board-certified by the American Board of Orthopaedic Surgery in general orthopaedics, with a certificate of added qualification for Sports Medicine.

Dr Anderson was a sports medicine specialist with an interest in knee injury and ligament reconstruction, and with special interest in children's injuries. He published more than 100 peer-reviewed journal articles and 26 book chapters, and received a patent for the invention of a paediatric ACL reconstruction system. Among numerous awards, three standouts were: being recognised as one of America's Top Physicians 2004-2012 from Consumer's Research Council, being elected to Best Doctors in America by his peers 20072008 and being Nashville Business Journal Top Doctor 2016-2017.

Dr Anderson had many prestigious positions through his life. He served as President of the American Orthopaedic Society for Sports Medicine from 2015 to 2016, and as an Associate Editor of The Orthopedic Journal of Sports Medicine and The American Journal of Sports Medicine.

Above all, he was a true friend and colleague whom you could go to with problems and challenges, not the least among our youngest patients. Allen will be greatly missed by us all.

\section{Author affiliations}

${ }^{1}$ Division of Physiotherapy, Linköping University, Linköping, Sweden

${ }^{2}$ School of Allied Health, La Trobe University, Melbourne, Australia

${ }^{3}$ Division of Orthopaedic Surgery, Oslo University Hospital, Oslo, Norway
${ }^{4}$ Oslo Sports Trauma Research Centre (OSTRC), Norwegian School of Sport Sciences, Oslo, Norway

${ }^{5}$ Institute of Clinical Medicine, University of Oslo, Oslo, Norway

${ }^{6}$ Department of Sports Medicine, Norwegian School of Sport Sciences, Oslo, Norway

${ }^{7}$ Tennessee Orthopaed Alliance, Nashville, Tennessee, USA

${ }^{8}$ Department of Pediatric Orthopaedic Surgery, Hôpital Femme Mere Enfant, Lyon,

France

${ }^{9}$ Orthopedic Department, Universidade Federal de São Paulo, São Paulo, Brazil

${ }^{10}$ Stockholm Sports Trauma Research Center, Karolinska Institute, Stockholm, Sweden

${ }^{11}$ Department of Orthopaedics, Children's Hospital of Philadelphia, Philadelphia, USA

${ }^{12}$ OrthoSport Victoria Research Unit, Epworth Healthcare, Melbourne, Australia

${ }^{13}$ College of Science, Health \& Engineering, La Trobe University, Melbourne, Australia

${ }^{14}$ Department of Orthopaedics, Sahlgrenska Academy, University of Gothenburg,

Gothenburg, Sweden

${ }^{15}$ Division of Sports Medicine, Boston Children's Hospital, Boston, USA

${ }^{16}$ Harvard Medical School, Boston, USA

${ }^{17}$ Steadman Philippon Research Institute, Vail, USA

${ }^{18}$ The Steadman Clinic, Vail, USA

${ }^{19}$ College of Engineering, Swansea University, Swansea, UK

${ }^{20}$ Santa Monica Orthopaedic and Sports Medicine Group, Los Angeles, USA

${ }^{21}$ The Micheli Center for Sports Injury Prevention, Waltham, USA

${ }^{22}$ University of Calgary Sports Medicine Centre, Calgary, Canada

${ }^{23}$ Department of Orthopaedics and Rehabilitation Medicine, University of Chicago,

Chicago, USA

${ }^{24}$ North Sydney Orthopaedic \& Sports Medicine Centre, Sydney, Australia

${ }^{25}$ Department of Orthopaedic Surgery, Centre Hospitalier Luxembourg, Luxembourg

${ }^{26}$ Sports Medicine Research Laboratory, Luxembourg Institute of Health, Luxembourg

${ }^{27}$ Institute for Anatomy and Cell Biology, Ruprecht-Karls-University, Heidelberg,

Germany

${ }^{28} \mathrm{HKF}$ International Center for Hip, Knee, Foot Surgery and Sports Traumatology,

ATOS Klinik, Heidelberg, Germany

${ }^{29}$ FIFA Medical Center of Excellence, Velocity Physical Therapy, Los Angeles, USA

${ }^{30}$ Medical \& Scientific Department, International Olympic Committee, Chateau de

Vidy, Lausanne, Switzerland

${ }^{31}$ Sport Injury Prevention Research Centre, Faculty of Kinesiology, University of

Calgary, Calgary, Alberta, Canada

${ }^{32}$ Department of Rehabilitation Sciences and Physiotherapy, Faculty of Medicine and Health Science, Ghent University, Ghent, Belgium

Correction notice This article has been updated since it was published Online First. The Competing Interests section has been updated.

Acknowledgements The authors would like to thank Cherine Touvet-Fahmy and Fiona Trabelsi from the IOC Medical \& Scientific Department for their help and support with all arrangements ahead of and during the Lausanne consensus meeting. The authors would like to thank Pontus Andersson from Pontus Art Production, Gothenburg, Sweden for the illustrations of surgical techniques. The authors gratefully acknowledge the contribution and support of the IOC Medical and Scientific Chair, Dr Uğur Erdener, during the consensus meeting, and the International Olympic Committee for funding the meeting. HM acknowledges Olympiatoppen Norway and Idrettens Helsesenter, Oslo, Norway.

Contributors CLA, GRE, LE, HG and HM made substantial contributions to overall and detailed conception, planning, drafting and critically revising the manuscript. CLA, GRE and HG wrote the first draft. AFA, FC, MC, MF, TJG, JAF, JK, MSK, RFLaP, MMcM, BM, LM, NM, BR, JR, RSe, RSi, HJS-G, TS and EW made substantial contributions to drafting and critically revising the manuscript. LE chaired the Lausanne consensus meeting. CLA co-ordinated and administered the Delphi surveys. CLA, LE and HM constructed the Delphi survey.

Funding The IOC funded the consensus meeting, but did not influence the content of this consensus statement.

Competing interests $M C$ is a paid consultant for Arthrex. LE is the Head of Scientific Activities in the Medical and Scientific Department of the International Olympic Committee, has received fees for speaking from Smith \& Nephew, has received research funding from Biomet and Smith \& Nephew, has received funds for an employee from Arthrex and Smith \& Nephew, has received royalties or fees for consulting from Arthrex and is an Editor of BJSM. MSK is a paid consultant for Best Doctors, OrthoPediatrics, Össur and Smith \& Nephew, receives royalties, financial or material support from OrthoPediatrics, Össur, Saunders/Mosby-Elsevier and Wolters Kluwer Health-Lippincott Williams \& Wilkins, is a paid member of the Steadman Philippon Research Institute, Scientific Advisory Committee, and is an unpaid board or committee member of the American Academy of Orthopaedic Surgeons, American Orthopaedic Society for Sports Medicine, Harvard Medical School, Harvard School of Public Health, Herodicus Society, Pediatric Orthopaedic Society of North America and Pediatric Research in Sports Medicine. RLaP receives royalties from Össur, Arthrex and Smith \& Nephew. BR receives royalties from Elsevier, salary from American Journal of Sports Medicine and Orthopaedic Journal of Sports Medicine, and holds stock in Merck and Johnson and Johnson. RSe is an unpaid board member 
and President of the European Society of Sports Traumatology Knee Surgery and Arthroscopy (ESSKA). TS works as Scientific Manager in the Medical and Scientific Department of the International Olympic Committee.

\section{Patient consent Obtained.}

Provenance and peer review Not commissioned; externally peer reviewed.

Open Access This is an Open Access article distributed in accordance with the terms of the Creative Commons Attribution (CC BY 4.0) license, which permits others to distribute, remix, adapt and build upon this work, for commercial use, provided the original work is properly cited. See: http://creativecommons.org/licenses/by/4.0/ (c) Article author(s) (or their employer(s) unless otherwise stated in the text of the article) 2018. All rights reserved. No commercial use is permitted unless otherwise expressly granted.

\section{REFERENCES}

1 Werner BC, Yang S, Looney AM, et al. Trends in pediatric and adolescent anterior cruciate ligament injury and reconstruction. J Pediatr Orthop 2016;36:447-52.

2 Shaw L, Finch CF. Trends in pediatric and adolescent anterior cruciate ligament injuries in Victoria, Australia 2005-2015. Int J Environ Res Public Health 2017;14:599.

3 Whittaker JL, Woodhouse LJ, Nettel-Aguirre A, et al. Outcomes associated with early post-traumatic osteoarthritis and other negative health consequences 3-10 years following knee joint injury in youth sport. Osteoarthritis Cartilage 2015;23:1122-9.

4 Moksnes $H$, Engebretsen L, Risberg MA. The current evidence for treatment of $\mathrm{ACL}$ injuries in children is low: a systematic review. J Bone Joint Surg Am 2012:94:1112-9.

5 Johnson VL, Roe JP, Salmon LJ, et al. Does age influence the risk of incident knee osteoarthritis after a traumatic anterior cruciate ligament injury? Am J Sports Med 2016:44:2399-405

6 van der Horst N, Backx F, Goedhart EA, et al. Return to play after hamstring injuries in football (soccer): a worldwide Delphi procedure regarding definition, medical criteria and decision-making. Br J Sports Med 2017;51:1583-91.

7 Eubank BH, Mohtadi NG, Lafave MR, et al. Using the modified Delphi method to establish clinical consensus for the diagnosis and treatment of patients with rotator cuff pathology. BMC Med Res Methodol 2016;16:56.

8 Donaldson A, Cook J, Gabbe B, et al. Bridging the gap between content and context: establishing expert consensus on the content of an exercise training program to prevent lower-limb injuries. Clin J Sport Med 2015;25:221-9.

9 Paterno MV, Rauh MJ, Schmitt LC, et al. Incidence of second ACL injuries 2 years after primary $A C L$ reconstruction and return to sport. Am J Sports Med 2014:42:1567-73.

10 Soligard T, Myklebust G, Steffen K, et al. Comprehensive warm-up programme to prevent injuries in young female footballers: cluster randomised controlled trial. BMJ 2008;337:a2469.

11 Mandelbaum BR, Silvers HJ, Watanabe DS, et al. Effectiveness of a neuromuscular and proprioceptive training program in preventing anterior cruciate ligament injuries in female athletes: 2-year follow-up. Am J Sports Med 2005;33:1003-10.

12 Sugimoto D, Myer GD, McKeon JM, et al. Evaluation of the effectiveness of neuromuscular training to reduce anterior cruciate ligament injury in female athletes: a critical review of relative risk reduction and numbers-needed-to-treat analyses. $\mathrm{Br} J$ Sports Med 2012;46:979-88.

13 Waldén $\mathrm{M}$, Atroshi I, Magnusson $\mathrm{H}$, et al. Prevention of acute knee injuries in adolescent female football players: cluster randomised controlled trial. BMJ 2012;344:e3042

14 Myklebust G, Engebretsen L, Braekken IH, et al. Prevention of anterior cruciate ligament injuries in female team handball players: a prospective intervention study over three seasons. Clin J Sport Med 2003:13:71-8.

15 Silvers-Granelli $\mathrm{H}$, Mandelbaum B, Adeniji 0 , et al. Efficacy of the FIFA 11+ injury prevention program in the collegiate male soccer player. Am J Sports Med 2015;43:2628-37.

16 Emery CA, Roy TO, Whittaker JL, et al. Neuromuscular training injury prevention strategies in youth sport: a systematic review and meta-analysis. Br J Sports Med 2015;49:865-70

17 Lauersen JB, Bertelsen DM, Andersen LB. The effectiveness of exercise interventions to prevent sports injuries: a systematic review and meta-analysis of randomised controlled trials. Br J Sports Med 2014;48:871-7.

18 Thorborg K, Krommes KK, Esteve E, et al. Effect of specific exercise-based football injury prevention programmes on the overall injury rate in football: a systematic review and meta-analysis of the FIFA 11 and 11+ programmes. Br J Sports Med 2017;51:562-71

19 Rössler R, Junge A, Bizzini M, et al. A multinational cluster randomised controlled trial to assess the efficacy of '11+ Kids': a warm-up programme to prevent injuries in children's football. Sports Med 2017.

20 Rössler R, Donath L, Bizzini $M$, et al. A new injury prevention programme for children's football--FIFA 11+ Kids--can improve motor performance: a clusterrandomised controlled trial. J Sports Sci 2016;34:549-56.
21 Attwood MJ, Roberts SP, Trewartha G, et al. Efficacy of a movement control injury prevention programme in adult men's community rugby union: a cluster randomised controlled trial. Br J Sports Med 2018;52:368-74.

22 Hägglund M, Atroshi I, Wagner $\mathrm{P}$, et al. Superior compliance with a neuromuscular training programme is associated with fewer $A C L$ injuries and fewer acute knee injuries in female adolescent football players: secondary analysis of an $\mathrm{RCT}$. $\mathrm{Br}$ J Sports Med 2013;47:974-9.

23 Soligard T, Nilstad A, Steffen K, et al. Compliance with a comprehensive warm-up programme to prevent injuries in youth football. Br J Sports Med 2010;44:787-93.

24 Steffen $\mathrm{K}$, Emery CA, Romiti $\mathrm{M}$, et al. High adherence to a neuromuscular injury prevention programme (FIFA 11+) improves functional balance and reduces injury risk in Canadian youth female football players: a cluster randomised trial. $\mathrm{Br} J$ Sports Med 2013:47:794-802.

25 Kaplan PA, Nelson NL, Garvin KL, et al. MR of the knee: the significance of high signal in the meniscus that does not clearly extend to the surface. AJR Am J Roentgenol 1991;156:333-6.

26 Thapa MM, Chaturvedi A, lyer RS, et al. MRI of pediatric patients: part 2, norma variants and abnormalities of the knee. AJR Am J Roentgenol 2012;198:W45 6-W465.

27 Kocher MS, DiCanzio J, Zurakowski D, et al. Diagnostic performance of clinical examination and selective magnetic resonance imaging in the evaluation of intraarticular knee disorders in children and adolescents. Am J Sports Med 2001;29:292-6.

28 Yellin JL, Fabricant PD, Gornitzky A, et al. Rehabilitation following anterior cruciate ligament tears in children: a systematic review. JBJS Rev 2016:4:e41-e415.

29 Bergeron MF, Mountjoy M, Armstrong N, et al. International Olympic Committee consensus statement on youth athletic development. $\mathrm{Br}$ J Sports Med 2015;49:843-51.

30 Ardern CL, Österberg A, Tagesson S, et al. The impact of psychological readiness to return to sport and recreational activities after anterior cruciate ligament reconstruction. Br J Sports Med 2014;48:1613-9.

31 Ardern CL, Webster KE, Taylor NF, et al. Return to sport following anterior cruciate ligament reconstruction surgery: a systematic review and meta-analysis of the state of play. Br J Sports Med 2011:45:596-606.

32 Podlog L, Dimmock J, Miller J. A review of return to sport concerns following injury rehabilitation: practitioner strategies for enhancing recovery outcomes. Phys Ther Sport 2011;12:36-42.

33 van Melick N, van Cingel RE, Brooijmans F, et al. Evidence-based clinical practice update: practice guidelines for anterior cruciate ligament rehabilitation based on a systematic review and multidisciplinary consensus. Br J Sports Med 2016;50:1506-15.

34 Ardern CL, Glasgow P, Schneiders A, et al. Consensus statement on return to sport from the First World Congress in Sports Physical Therapy, Bern. Br J Sports Med 2016;2016:853-64.

35 Grindem $\mathrm{H}$, Eitzen I, Engebretsen L, et al. Nonsurgical or surgical treatment of $\mathrm{ACL}$ injuries: knee function, sports participation, and knee reinjury: the Delaware-Oslo ACL Cohort Study. J Bone Joint Surg Am 2014;96:1233-41.

36 Grindem H, Snyder-Mackler L, Moksnes H, et al. Simple decision rules can reduce reinjury risk by $84 \%$ after $\mathrm{ACL}$ reconstruction: the Delaware-Oslo $\mathrm{ACL}$ cohort study. Br J Sports Med 2016;50:804-8.

37 Kvist J, Kartus J, Karlsson J, et al. Results from the Swedish national anterior cruciate ligament register. Arthroscopy 2014;30:803-10.

38 Dekker TJ, Godin JA, Dale KM, et al. Return to sport after pediatric anterior cruciate ligament reconstruction and its effect on subsequent anterior cruciate ligament injury. J Bone Joint Surg Am 2017;99:897-904.

39 Kyritsis P, Bahr R, Landreau P, et al. Likelihood of ACL graft rupture: not meeting six clinical discharge criteria before return to sport is associated with a four times greater risk of rupture. Br J Sports Med 2016;50:946-51.

40 Johnsen MB, Eitzen I, Moksnes $\mathrm{H}$, et al. Inter- and intrarater reliability of four singlelegged hop tests and isokinetic muscle torque measurements in children. Knee Surg Sports Traumatol Arthrosc 2015;23:1907-16.

41 Thomeé R, Kaplan Y, Kvist J, et al. Muscle strength and hop performance criteria prior to return to sports after ACL reconstruction. Knee Surg Sports Traumatol ArthrosC 2011;19:1798-805.

42 Moksnes H, Engebretsen L, Seil R. The ESSKA paediatric anterior cruciate ligament monitoring initiative. Knee Surg Sports Traumatol Arthrosc 2016;24:680-7.

43 Frosch $\mathrm{KH}$, Stengel D, Brodhun T, et al. Outcomes and risks of operative treatment of rupture of the anterior cruciate ligament in children and adolescents. Arthroscopy 2010;26:1539-50.

44 Kocher MS, Saxon HS, Hovis WD, et al. Management and complications of anterior cruciate ligament injuries in skeletally immature patients: survey of the Herodicus Society and The ACL Study Group. J Pediatr Orthop 2002;22:452-7.

45 Seil R, Weitz FK, Pape D. Surgical-experimental principles of anterior cruciate ligament $(A C L)$ reconstruction with open growth plates. J Exp Orthop 2015;2:11

46 Calvo R, Figueroa D, Gili F, et al. Transphyseal anterior cruciate ligament reconstruction in patients with open physes: 10-year follow-up study. Am J Sports Med 2015;43:289-94 
47 Cohen M, Ferretti M, Quarteiro M, et al. Transphyseal anterior cruciate ligament reconstruction in patients with open physes. Arthroscopy 2009;25:831-8.

48 Fabricant PD, Kocher MS. Management of ACL injuries in children and adolescents. J Bone Joint Surg Am 2017;99:600-12.

49 Hui C, Roe J, Ferguson D, et al. Outcome of anatomic transphyseal anterior cruciate ligament reconstruction in Tanner stage 1 and 2 patients with open physes. Am J Sports Med 2012;40:1093-8.

50 Kocher MS, Smith JT, Zoric BJ, et al. Transphyseal anterior cruciate ligament reconstruction in skeletally immature pubescent adolescents. J Bone Joint Surg Am 2007:89:2632-9.

51 Siebold R, Takada T, Feil S, et al. Anatomical "C "-shaped double-bundle versus single-bundle anterior cruciate ligament reconstruction in pre-adolescent children with open growth plates. Knee Surg Sports Traumatol Arthrosc 2016;24:796-806.

52 Janarv PM, Wikström B, Hirsch G. The influence of transphyseal drilling and tendon grafting on bone growth: an experimental study in the rabbit. J Pediatr Orthop 1998;18:149-54.

53 Kocher MS, Garg S, Micheli LJ. Physeal sparing reconstruction of the anterior cruciate ligament in skeletally immature prepubescent children and adolescents. Surgical technique. J Bone Joint Surg Am 2006;88:283-93.

54 Anderson AF. Transepiphyseal replacement of the anterior cruciate ligament using quadruple hamstring grafts in skeletally immature patients. J Bone Joint Surg Am 2004;86-A:201-9.

55 Andrews M, Noyes FR, Barber-Westin SD. Anterior cruciate ligament allograft reconstruction in the skeletally immature athlete. Am J Sports Med 1994;22:48-54.

56 Henry J, Chotel F, Chouteau J, et al. Rupture of the anterior cruciate ligament in children: early reconstruction with open physes or delayed reconstruction to skeletal maturity? Knee Surg Sports Traumatol Arthrosc 2009;17:748-55.

57 Lo IK, Kirkley A, Fowler PJ, et al. The outcome of operatively treated anterior cruciate ligament disruptions in the skeletally immature child. Arthroscopy 1997;13:627-34.

58 Kaeding CC, Pedroza AD, Reinke EK, et al. Risk factors and predictors of subsequent $A C L$ injury in either knee after $A C L$ reconstruction: prospective analysis of 2488 primary ACL reconstructions from the MOON Cohort. Am J Sports Med 2015:43:1583-90.

59 Tejwani SG, Chen J, Funahashi TT, et al. Revision risk after allograft anterior cruciate ligament reconstruction. Am J Sports Med 2015:43:2696-705.

60 Scheffler SU, Schmidt T, Gangéy l, et al. Fresh-frozen free-tendon allografts versus autografts in anterior cruciate ligament reconstruction: delayed remodeling and inferior mechanical function during long-term healing in sheep. Arthroscopy 2008:24:448-58

61 Goddard M, Bowman N, Salmon LJ, et al. Endoscopic anterior cruciate ligament reconstruction in children using living donor hamstring tendon allografts. $A m$ J Sports Med 2013:41:567-74.

62 Zebis MK, Bencke J, Andersen LL, et al. The effects of neuromuscular training on knee joint motor control during sidecutting in female elite soccer and handball players. Clin J Sport Med 2008;18:329-37.

63 Zebis MK, Andersen LL, Bencke J, et al. Identification of athletes at future risk of anterior cruciate ligament ruptures by neuromuscular screening. Am J Sports Med 2009:37:1967-73.

64 Fleming BC, Spindler KP, Palmer MP, et al. Collagen-platelet composites improve the biomechanical properties of healing anterior cruciate ligament grafts in a porcine model. Am J Sports Med 2009;37:1554-63.

65 Murray MM. Current status and potential of primary ACL repair. Clin Sports Med 2009;28:51-61.

66 Magarian EM, Vavken P, Murray MM. Human anterior cruciate ligament fibroblasts from immature patients have a stronger in vitro response to platelet concentrates than those from mature individuals. Knee 2011;18:247-51.

67 Proffen BL, Fleming BC, Murray MM. Histologic predictors of maximum failure loads differ between the healing ACL and ACL Grafts after 6 and 12 Months In Vivo. Orthop J Sports Med 2013;1:232596711351245.

68 Meller R, Willbold E, Hesse E, et al. Histologic and biomechanical analysis of anterior cruciate ligament graft to bone healing in skeletally immature sheep. Arthroscopy 2008;24:1221-31.

69 Kopf S, Schenkengel JP, Wieners G, et al. No bone tunnel enlargement in patients with open growth plates after transphyseal ACL reconstruction. Knee Surg Sports Traumatol Arthrosc 2010;18:1445-51.

70 Bollen S, Pease F, Ehrenraich A, et al. Changes in the four-strand hamstring graft in anterior cruciate ligament reconstruction in the skeletally-immature knee. J Bone Joint Surg Br 2008;90:455-9.

71 Astur DC, Cachoeira CM, da Silva Vieira T, et al. Increased incidence of anterior cruciate ligament revision surgery in paediatric verses adult population. Knee Surg Sports Traumatol Arthrosc 2017.

72 Astur DC, Arliani GG, Debieux P, et al. Intraarticular hamstring graft diameter decreases with continuing knee growth after $\mathrm{ACL}$ reconstruction with open physes. Knee Surg Sports Traumatol Arthrosc 2016;24:792-5.

73 Seil R, Weitz F, Menetrey J, et al. Anatomical and technical considerations for pediatric $A C L$ reconstruction. Nakamura N, ed. Controversies in the technical aspects of $A C L$ reconstruction. Heidelberg, Germany: Springer-Verlag, 2017:61-72.

74 Tanner JM. Growth at adolescence. Springfield, IL: Thomas, 1962.
75 Gilsanz V, Ratib O. Hand bone age: a digital atlas of skeletal maturity. Heidelberg, Germany: Springer-Verlag, 2011.

76 Greulich W, Pyle SI. Radiographic atlas of skeletal development of the hand and wrist. Stanford University Press: Stanford, CA, 1959

77 Krych AJ, Pitts RT, Dajani KA, et al. Surgical repair of meniscal tears with concomitant anterior cruciate ligament reconstruction in patients 18 years and younger. Am J Sports Med 2010;38:976-82.

78 Kocher MS, Garg S, Micheli LJ. Physeal sparing reconstruction of the anterior cruciate ligament in skeletally immature prepubescent children and adolescents. J Bone Joint Surg Am 2005;87:2371-9.

79 Anderson AF, Anderson CN. Correlation of meniscal and articular cartilage injuries in children and adolescents with timing of anterior cruciate ligament reconstruction. Am J Sports Med 2015;43:275-81.

80 Lawrence JT, Argawal N, Ganley TJ. Degeneration of the knee joint in skeletally immature patients with a diagnosis of an anterior cruciate ligament tear: is there harm in delay of treatment? Am J Sports Med 2011;39:2582-7.

81 Newman JT, Carry PM, Terhune EB, et al. Factors predictive of concomitant injuries among children and adolescents undergoing anterior cruciate ligament surgery. Am J Sports Med 2015:43:282-8.

82 Funahashi KM, Moksnes H, Maletis GB, et al. Anterior cruciate ligament injuries in adolescents with open physis: effect of recurrent injury and surgical delay on meniscal and cartilage injuries. Am J Sports Med 2014;42:1068-73.

83 Moksnes H, Engebretsen L, Eitzen I, et al. Functional outcomes following a nonoperative treatment algorithm for anterior cruciate ligament injuries in skeletally immature children 12 years and younger. A prospective cohort with 2 years followup. Br J Sports Med 2013;47:488-94.

84 Edwards TB, Greene CC, Baratta RV, et al. The effect of placing a tensioned graft across open growth plates. A gross and histologic analysis. J Bone Joint Surg Am 2001:83-A:7725-34.

85 Chudik S, Beasley L, Potter $\mathrm{H}$, et al. The influence of femoral technique for graft placement on anterior cruciate ligament reconstruction using a skeletally immature canine model with a rapidly growing physis. Arthroscopy 2007;23:1309-19.

86 Chotel F, Henry J, Seil R, et al. Growth disturbances without growth arrest after ACL reconstruction in children. Knee Surg Sports Traumatol Arthrosc 2010;18:1496-500.

87 Andernord D, Desai N, Björnsson H, et al. Predictors of contralateral anterior cruciate ligament reconstruction: a cohort study of 9061 patients with 5-year follow-up. Am J Sports Med 2015:43:295-302.

88 Wiggins AJ, Grandhi RK, Schneider DK, et al. Risk of secondary injury in younger athletes after anterior cruciate ligament reconstruction: a systematic review and meta-analysis. Am J Sports Med 2016;44:1861-76.

89 Kay J, Memon M, Marx RG, et al. Over $90 \%$ of children and adolescents return to sport after anterior cruciate ligament reconstruction: a systematic review and metaanalysis. Knee Surg Sports Traumatol Arthrosc 2018.

90 Cohen M, Amaro JT, Ejnisman B, et al. Anterior cruciate ligament reconstruction after 10 to 15 years: association between meniscectomy and osteoarthrosis. Arthroscopy 2007;23:629-34

91 Pujol N, Beaufils P. Healing results of meniscal tears left in situ during anterior cruciate ligament reconstruction: a review of clinical studies. Knee Surg Sports Traumatol Arthrosc 2009:17:396-401.

92 Wyatt RW, Inacio MC, Liddle KD, et al. Factors associated with meniscus repair in patients undergoing anterior cruciate ligament reconstruction. Am J Sports Med 2013:41:2766-71.

93 Brophy RH, Wright RW, David TS, et al. Association between previous meniscal surgery and the incidence of chondral lesions at revision anterior cruciate ligament reconstruction. Am J Sports Med 2012;40:808-14

94 Nwachukwu BU, McFeely ED, Nasreddine A, et al. Arthrofibrosis after anterior cruciate ligament reconstruction in children and adolescents. J Pediatr Orthop 2011;31:811-7

95 Bansal A, Lamplot JD, VandenBerg J, et al. Meta-analysis of the risk of infections after anterior cruciate ligament reconstruction by graft type. Am J Sports Med 2017:036354651771445.

96 Renström P, Johnson RJ. Anatomy and biomechanics of the menisci. Clin Sports Med 1990;9:523-38

97 Crues JV, Mink J, Levy TL, et al. Meniscal tears of the knee: accuracy of MR imaging. Radiology 1987;164:445-8.

98 Malatray M, Raux S, Peltier A, et al. Ramp lesions in ACL deficient knees in children and adolescent population: a high prevalence confirmed in intercondylar and posteromedial exploration. Knee Surg Sports Traumatol Arthrosc 2017.

99 DePhillipo NN, Cinque ME, Chahla J, et al. Incidence and detection of meniscal ramp lesions on magnetic resonance imaging in patients with anterior cruciate ligament reconstruction. Am J Sports Med 2017:45:2233-7.

100 Krych AJ, McIntosh AL, Voll AE, et al. Arthroscopic repair of isolated meniscal tears in patients 18 years and younger. Am J Sports Med 2008;36:1283-9.

101 Shieh AK, Edmonds EW, Pennock AT. Revision meniscal surgery in children and adolescents: risk factors and mechanisms for failure and subsequent management. Am J Sports Med 2016;44:838-43. 
102 Dumont GD, Hogue GD, Padalecki JR, et al. Meniscal and chondral injuries associated with pediatric anterior cruciate ligament tears: relationship of treatment time and patient-specific factors. Am J Sports Med 2012;40:2128-33.

103 Guenther ZD, Swami V, Dhillon SS, et al. Meniscal injury after adolescent anterior cruciate ligament injury: how long are patients at risk? Clin Orthop Relat Res 2014;472:990-7.

104 Moksnes H, Engebretsen L, Risberg MA. Prevalence and incidence of new meniscus and cartilage injuries after a nonoperative treatment algorithm for $\mathrm{ACL}$ tears in skeletally immature children: a prospective MRI study. Am J Sports Med 2013:41:1771-9.

105 Mayer S, Albright JC, Stoneback JW. Pediatric knee dislocations and physeal fractures about the knee. J Am Acad Orthop Surg 2015;23:571-80.

106 Williams BT, James EW, LaPrade RF. A physeal-sparing fibular collateral ligament and proximal tibiofibular joint reconstruction in a skeletally immature athlete. Knee Surg Sports Traumatol Arthrosc 2016;24:661-5.

107 Kocher MS, Shore B, Nasreddine AY, et al. Treatment of posterior cruciate ligament injuries in pediatric and adolescent patients. J Pediatr Orthop 2012;32:553-60.

108 Warme WJ, Mickelson D. All-epiphyseal semitendinosus PCL reconstruction in a 10-year-old child. J Pediatr Orthop 2010;30:465-8.

109 LaPrade RF, Smith SD, Wilson KJ, et al. Quantification of functional brace forces for posterior cruciate ligament injuries on the knee joint: an in vivo investigation. Knee Surg Sports Traumatol Arthrosc 2015;23:3070-6.

110 Davis JC, Bryan S. Patient Reported Outcome Measures (PROMs) have arrived in sports and exercise medicine: why do they matter? Br J Sports Med 2015;49:1545-6

111 Solans M, Pane S, Estrada MD, et al. Health-related quality of life measurement in children and adolescents: a systematic review of generic and disease-specific instruments. Value Health 2008;11:742-64.

112 Schmidt LJ, Garratt AM, Fitzpatrick R. Child/parent-assessed population health outcome measures: a structured review. Child Care Health Dev 2002;28:227-37.

113 Brock DW. The ideal of shared decision making between physicians and patients. Kennedy Inst Ethics J 1991;1:28-47.

114 Brighouse H, Swift A. Family values: the ethics of parent-child relationships. Princeton: Princeton University Press, 2014.

115 Buchanan AE, Brock DW. Deciding for others: the ethics of surrogate decisionmaking. Cambridge, UK: Cambridge University Press, 1989.

116 Beauchamp TL, Childress JF. Principles of biomedical ethics. New York, NY: Oxford University Press, 2001.

117 Holt NL, Knight CJ. Parenting in youth sport: from research to practice. Abingdon: Routledge, 2014.

118 Archard D. Children: Rights and childhood. Abingdon: Routledge, 2014.

119 Gheaus A. Children's vulnerability and legitimate authority over children. J App/ Philos 2017.

120 Langford G. Education, persons and society. London: Macmillan, 1985.

121 Malina RM. Growth. In: Mooren FC, ed. Encyclopedia of exercise medicine in health and disease. Heidelberg: Springer, 2012:376-8.

122 McCullough LB. Contributions of ethical theory to pediatric ethics: pediatricians and parents as co-fiduciaries of pediatric patients. Miller G, ed. Pediatric bioethics. Cambridge, UK: Cambridge University Press, 2009:11-24.
123 Tamin J. Models of occupational medicine practice: an approach to understanding moral conflict in "dual obligation" doctors. Med Health Care Philos 2013;16:499-506.

124 Alderson P. Children's consent to surgery. Buckingham, England: Open University Press, 1993

125 Gert B, Clouser KD, Culver C. Bioethics: a return to fundamentals. New York: Oxford University Press, 1997.

126 Wall J. Ethics in light of childhood. Washington, DC: Georgetown University Press, 2010.

127 Ekås GR, Ardern C, Grindem H, et al. New meniscal tears after ACL injury: what is the risk? A systematic review protocol. Br J Sports Med 2018;52:386.

128 Hullmann SE, Ryan JL, Ramsey RR, et al. Measures of general pediatric quality of life: Child Health Questionnaire (CHQ), DISABKIDS Chronic Generic Measure (DCGM), KINDL-R, Pediatric Quality of Life Inventory (PedsQL) 4.0 Generic Core Scales, and Quality of My Life Questionnaire (QoML). Arthritis Care Res 2011;63(Suppl 11):S420-\$430

129 Varni JW, Seid M, Rode CA. The PedsQL: measurement model for the pediatric quality of life inventory. Med Care 1999;37:126-39.

130 Irwin DE, Varni JW, Yeatts $\mathrm{K}$, et al. Cognitive interviewing methodology in the development of a pediatric item bank: a patient reported outcomes measurement information system (PROMIS) study. Health Qual Life Outcomes 2009;7:3.

131 Kocher MS, Smith JT, Iversen MD, et al. Reliability, validity, and responsiveness of a modified International Knee Documentation Committee Subjective Knee Form (PediIKDC) in children with knee disorders. Am J Sports Med 2011;39:933-9.

132 Örtqvist M, Roos EM, Broström EW, et al. Development of the knee injury and osteoarthritis outcome Score for children (KOOS-Child): comprehensibility and content validity. Acta Orthop 2012;83:666-73.

133 Fabricant PD, Robles A, Downey-Zayas T, et al. Development and validation of a pediatric sports activity rating scale: the Hospital for Special Surgery Pediatric Functional Activity Brief Scale (HSS Pedi-FABS). Am J Sports Med 2013;41:2421-9

134 Kopelman LM. The best-interests standard as threshold, ideal, and standard of reasonableness. J Med Philos 1997;22:271-89.

135 Diekema DS. Parental refusals of medical treatment: the harm principle as threshold for state intervention. Theor Med Bioeth 2004:25:243-64.

136 Gillam L. The zone of parental discretion: an ethical tool for dealing with disagreement between parents and doctors about medical treatment for a child. Clin Ethics 2016;11:1-8.

137 Kilham H, Isaacs D, Kerridge I. When refusal is only distantly or unpredictably lifethreatening. In: McDougall R, Delaney C, Gillam L, eds. When doctors and parents disagree: ethics, paediatrics and the zone of parental discretion. Sydney, Australia: Federation Press, 2016

138 DeMarco JP, Powell DP, Stewart DO. Best interest of the child: surrogate decision making and the economics of externalities. J Bioeth Inq 2011;8:289-98.

139 Rhodes R, Holzman IR. The not unreasonable standard for assessment of surrogates and surrogate decisions. Theor Med Bioeth 2004;25:367-86.

140 Nair T, Savulescu J, Everett J, et al. Settling for second best: when should doctors agree to parental demands for suboptimal medical treatment? J Med Ethics 2017:43:831-40 